\title{
Nucleation of Slip-Weakening Rupture Instability in Landslides by Localized Increase of Pore Pressure
}

\section{Citation}

Viesca, Robert C., and James R. Rice. 2012. Nucleation of slip-weakening rupture instability in landslides by localized increase of pore pressure. Journal of Geophysical Research: Solid Earth 117: B03104.

\section{Published Version}

dx.doi.org/10.1029/2011JB008866

\section{Permanent link}

http://nrs.harvard.edu/urn-3:HUL.InstRepos:10859956

\section{Terms of Use}

This article was downloaded from Harvard University's DASH repository, and is made available under the terms and conditions applicable to Open Access Policy Articles, as set forth at http:// nrs.harvard.edu/urn-3:HUL.InstRepos:dash.current.terms-of-use\#OAP

\section{Share Your Story}

The Harvard community has made this article openly available.

Please share how this access benefits you. Submit a story.

Accessibility 
JOURNAL OF GEOPHYSICAL RESEARCH, VOL. ???, XXXX, DOI:10.1029/,

Submitted to J. Geophys. Res. - Solid Earth on 16 September 2011, revised 8 January 2012, accepted 25 January 2012, and sent in this form to JGR on 31 January 2012.

\title{
Nucleation of slip-weakening rupture instability in landslides by localized increase of pore pressure
}

\author{
Robert C. Viesca, ${ }^{1,2}$ James R. Rice, ${ }^{3}$ \\ Published 17 March 2012; reference to published version: \\ JOURNAL OF GEOPHYSICAL RESEARCH, VOL. 117, \\ B03104, doi:10.1029/2011JB008866, 21 pages, 2012. \\ Abstract.
}

\begin{abstract}
We model landslide initiation as slip surface growth driven by local elevated pore pressure, with particular reference to submarine slides. Assuming an elastic medium and friction that weakens with slip, solutions exist in which the slip surface may dynamically grow, without further pore pressure increases, at a rate of the order of the sediment shear wave speed, a situation comparable to earthquake nucleation. The size of the rupture at this transition point depends weakly on the imposed pore pressure profile; however, the amount of slip at the transition depends strongly on whether the pore pressure was broadly or sharply elevated. Sharper profiles may result in pore pressures reaching the total slope-normal stress before dynamic rupture is nucleated. While we do not account for modes of failure other than pure slip on a failure surface, this may be an indication that additional modes involving liquefaction or hydraulic cracking may be factors in the initiation of shallow slope failure. We identify two lengthscales, one geometrical ( $h$, depth below the free surface) and one material ( $\ell$, determined by the frictional weakening rate) and a transition in nucleation behavior between effectively "deep" and "shallow" limits dependent on their ratio. Whether dynamic propagation of failure is indefinite or arresting depends largely on whether the background shear stress is closer to nominal peak or residual frictional strength. This is determined in part by background pore pressures, and to consider the submarine case we simplify a common sedimentation/consolidation approach to reflect interest in near-seafloor conditions.
\end{abstract}

\section{Introduction}

\subsection{Narrow shear zones in landslides}

Landslides on land have often been observed to occur as slip on a localized shear surface within the soil column. The excavation of a failed clay slope in Selborne England, where failure was artificially triggered by fluid injection under experimental conditions, revealed a shear zone of $\mathrm{mm}$ thickness within a cm-scale disturbed zone, creating an arcuate shape that extended to a peak depth of $4 \mathrm{~m}$ below the slope surface [Cooper et al., 1998]. Trenching following a naturally (rainfall) induced slope failure revealed a disturbed zone $2-20 \mathrm{~mm}$ thick occurring within decomposed granite or within clay seams at comparable $2-5 \mathrm{~m}$ depths [Wen and Aydin 2003, 2004]. Similar to the Selborne failure, much of the downslope displacement was inferred to have occurred over shear zones $<5 \mathrm{~mm}$ thick. Extensive observations of landslides in southern Italy show extended periods of slow, downslope motion [summarized in Picarelli et al., 2005]. In addition to excavation of the slip surface, string inclinometers were used to infer the displacement profile with depth over time and shear was observed to occupy a thickness at or below the resolution of the inclinometers $(\sim 50 \mathrm{~cm})[P i$ carelli et al., 1995; Pellegrino et al., 2004]. Slip surfaces have

\footnotetext{
${ }^{1}$ School of Engineering and Applied Sciences, Harvard University, Cambridge, Massachusetts, USA.

${ }^{2}$ Now at the Department of Civil and Resource Engineering, Dalhousie University, Halifax, Nova Scotia, Canada.

${ }^{3}$ School of Engineering and Applied Sciences and Department of Earth and Planetary Sciences, Harvard University, Cambridge, Massachusetts, USA.
}

Copyright 2012 by the American Geophysical Union. $0148-0227 / 12 / \$ 9.00$ also been detected in landslides at quite shallow depths. In a landslide induced by artificial rainfall, the deflection of a buried rod with strain gauges attached at $10-\mathrm{cm}$ spacings gave an indication that a shear zone developed below the strain gauge resolution at depths ranging from 0.6-1.2 m [Ochiai et al., 2004]. Discontinuties in displacement may occur laterally as well, as observed by geodetic data from the steadily creeping Slumgullion earthflow [Gomberg et al. 1995].

Despite much lower resolution of observation in the submarine environment, there remains evidence to suggest that downslope motion may occur as translation of material overlying a shear zone that is thin relative to its depth. One indication is simply the apparent slide morphology with an example being the Gaviota slide off of the California coast. The slide is a sheet-like failure bounded by upslope detatchment and thrusting out of the apparent failure plane occurring at the toe [Edwards et al., 1995]. Furthermore, an open gap that is colinear with the landslide headscarp and extends for several kilometers indicates that the adjacent regions started to move downslope. At its largest, the gap is 2 $\mathrm{m}$ deep (compared to 6-8 $\mathrm{m}$ deep headscarp of the adjacent failure) and $10 \mathrm{~m}$ wide, however high resolution $(<1 \mathrm{~m}$ in depth) seismic data show no apparent signs of disturbance from the sediment deformation, consistent with initial slip on a surface-parallel rupture [Blum et al., 2010]. Limits on resolution are also partially compensated by the accessibility through seismic data of failures preserved under deep sediment drapes. Offshore Angola, Gee et al. [2005] uncovered blocks of sediment with seismically intact stratigraphy that had been transported downslope several kilometers. The dimensions of the blocks themselves reach several kilometers in length and are approximately $100 \mathrm{~m}$ in depth. In such instances there is often mentioned a "weak horizon" implying that for the stratigraphy to remain as parallel reflectors, downslope movement is translational with shear localized to a basal layer. 
Such localized deformation may be expected for materials that weaken with shear. The Selborne event occurred in overconsolidated sediments (i.e., soils that have previously supported greater overburden than at present), for which such weakening is commonly known to exist and is demonstrated, for example, in ring shear tests where localized deformation is kinematically enforced [e.g., Bishop et al., 1971] or in a triaxial cell in which weakening occurs and localization is allowed to develop spontaneously. In contrast to overconsolidated sediments, normally consolidated sediments (i.e., soils whose current overburden is the largest ever supported) are thought to strengthen with shear. However, while marine sediments are ideally considered as normally consolidated, given typical sedimentation rates on these slopes $(\sim \mathrm{mm} / \mathrm{yr}$ or less) strength may develop due to the long lifetime of interparticle contacts. Such behavior is indicated by increased sample stiffness following long periods of fixed loads in consolidation tests [e.g., Karig and Ask, 2003]; by the development of increasingly peaked stress-strain profiles under triaxial loading conditions for normally consolidated samples previously held under loads for increasingly long times [e.g., Bjerrum and Lo, 1963]; as well as evidence of strength regain in ring-shear tests after a period of fixed displacement [e.g., Stark et al., 2005; Carrubba and Del Fabro, 2008; and Stark and Hussain, 2010]. Such strength would be lost upon sufficient disruption of contacts (i.e., the sediments are considered sensitive), and if weakening is sufficiently strong, localized deformation may be expected as for overconsolidated sediments.

\subsection{Previous fracture modeling of landslide and avalanche initiation}

That weakening leads to localized deformation has been a basis for theoretical work on slope stability, with the shear zone approximated as a discontinuity in shear displacement (slip, $\delta$ ) occurring across a surface. This representation has the advantage that stress and displacements in the slope may be readily calculated for a given distribution of slip or stress on the discontinuity [as in Muller and Martel, 2000; Martel, 2004]. The work on initiation has most commonly been done under the assumption of linear elastic behavior of sediments in response to slip parallel to a free surface at a depth $h$; and that the shear strength on the slip surface weakens from a peak $\tau_{p}$ to residual value $\tau_{r}$ over a characteristic amount of slip $\delta_{c}$. The purpose of this line of work has been to examine conditions under which the slipping region will propagate without external forcing (other than gravity).

Much of the work in this field has assumed a priori that the unstable rupture length will be much longer than the depth. As a result of this assumption, the analyses can reasonably neglect the deformation of the material underlying the slip surface and also presume that the overlying material undergoes a uniform compression or extension in response to the slip. This may seem reasonable for submarine slope failures where lengths often exceed a kilometer (we will later find this assumption reasonable provided the slip surface is relatively shallow). The first work in this vein was that of Palmer and Rice [1973] who examined the scenario of a slipsurface induced by the relief of stress from a cut in a slope. McClung [1979] extended this analysis to the representation of snow slab avalanches for the case when the crack originates not from a cut in the slope, but within the slope itself. Puzrin et al. [2004] performed a similar analysis in the landslide context. An additional simplifying assumption in much of the above work is that the weakening from peak to residual occurs over a distance from the rupture tip that is small compared to the depth. This so-called small-scaleyielding assumption effectively presumes that the strength of the slipping surface is at the residual level over the length of the crack. While keeping the shallow depth assumption, this assumption of small-scale-yielding was relaxed in subsequent work [Cleary and Rice, 1974; Bazant et al., 2003; Puzrin et al., 2004; Puzrin and Germanovich, 2005; and McClung, 2009].

In this shallow depth limit, the crack length at which propagation occurs was found to scale with the length

$$
\sqrt{\frac{E^{*} h \delta_{c}}{\tau_{p}-\tau_{r}}}
$$

where $E^{*}=2 \mu /(1-\nu)$ as the plane-strain modulus relating stress changes to the extension and compression of the overlying material (and $\mu$ and $\nu$ are the shear modulus and Poisson ratio). Recent work has begun to consider finite aspect ratios of crack length to depth. Studying the initiation of snow-slab avalanches by the presence of uniformly weak regions in the slipping zone, Bazant et al. [2003] assumed both a finite slip-weakening region and burial depth, but treated the underlying material as rigid, as is effectively assumed in the shallow crack limit. In this work we will explore the transition in behavior from that of a deeply buried slip surface to that in a shallow limit for finite-size weakening zones.

The above work lies in parallel to that pursued in mechanics of faulting, akin to a deeply buried limit [e.g., Ida, 1972]. Uenishi and Rice [2003] studied the quasistatic growth of slip-weakening shear fracture in a linear elastic medium by a locally increasing concentration of shear stress on the fault. They observed that the fracture may reach a length at which its growth may continue without further increases in shear stress, corresponding to the nucleation of a dynamically propagating rupture. Furthermore, the key result was their observation that, so long as shear strength weakened linearly with slip (with slope $\left.\left(\tau_{p}-\tau_{r}\right) / \delta_{c}\right)$, this critical length was independent of the shape of the shear stress concentration. At this nucleation limit, they showed that the problem reduced to a eigenvalue problem the smallest eigenvalue of which corresponds to the critical length, approximately

$$
0.579 \frac{\mu^{*} \delta_{c}}{\tau_{p}-\tau_{r}}
$$

where $\mu^{*}$ is $\mu /(1-\nu)$ for mode II (slip in the direction of rupture propagation, as assumed for work above) and $\mu$ for mode III (slip direction normal to rupture propagation). In this work we will arrive at a comparable eigenvalue problem to find the critical length under similar conditions near a free surface. While nucleation under slip-weakening friction continues to be of interest for some dynamic rupture models [e.g., Bizzarri, 2010], experiments indicate that friction on faults at the slow slip rates of the nucleation stage may be better represented by a slip rate and state dependence and consequently, there has been a shift of focus to nucleation under this condition [Tse and Rice, 1986; Dieterich, 1992; Lapusta et al., 2000; Rubin and Ampuero, 2005; Ampuero and Rubin, 2008; Rubin and Ampuero 2009].

\subsection{Extension to account for local sources of pore pressure}

Within the landslide context, what has yet to be thoroughly studied in fracture growth is the role of the triggering mechanism, the most commonly cited of which is an increase in pore pressure. Rather than static increases in levels of shear stress, the effective stress is reduced, lowering the frictional contribution to shear strength. Of interest here is the growth of a thin shear rupture in direct response to local elevations of pore pressure, and how such local slip may catastrophically grow to induce failure over a 
much larger area. To isolate this response, we exclude potential for weakening other than that induced by slip. This is in slight contrast to work that seeks to couple this effect with the potential formation and coalescence of weakened, but not necessarily localized, regions of deformation to explain apparent acceleration of deformation over days prior to failure [Kilburn and Petley, 2003; Petley et al., 2005]. For the infinite-slope-type problems considered for fracture propagation, promising work in this direction explored both shear-stress and pore-pressure loading via a finite element discretization of a shear-softening basal layer lying above a rigid boundary layer and below an elastic-ideally plastic material [Wiberg et al., 1990]. Of particular interest here is how localized failure may propagate while pore pressure remains at a level below confining stress levels, at which point conditions may be met for liquefaction (a complete loss of sediment shear strength, typically assumed here to be frictionally determined) or the opening of a hydraulic fracture. Our intention is not to exclude these possibilities, which are beyond the scope of this paper, and indeed we will find in the course of this study that such scenarios may not be easily avoidable in certain environments.

Observations have been made where pore pressures remain below confining stresses and induced slip extends over a region larger than that of local elevation. In the Selborne experiment [Cooper et al., 1998], failure was triggered within the overconsolidated clay by injecting water over a period of several months. In the days preceding failure, the pore pressures averaged along the eventual slip surface (as estimated from that of adjacent piezometers) reached only approximately $15 \%$ of the vertical overburden. That is this well below probable lithostatic stress levels and also well below what would generally be expected for initiation of failure with the nominal slope angle $\left(\sim 25^{\circ}\right)$. However, when examining the distribution of pore pressure along the slip surface, the authors find a pronounced peak approximately midslope, during a period of slow movement 12 days before catastrophic collapse. The highest pore pressure in that local peak is approximately $48 \mathrm{kPa}$ at $4.2 \mathrm{~m}$ below the surface. With an estimated bulk soil unit weight a factor 1.7-2 times that of water, this pore pressure seems sufficient to induce localized slip while remaining below lithostatic stresses.

A well-instrumented hillslope hollow in the Oregon Coast Range underwent recorded changes in head with depth during a rainstorm that precipitated a shallow $(\sim 0.5 \mathrm{~m}-$ deep) landslide [Montgomery et al., 2009]. There, frictional strength alone would be insufficient to maintain the soil on such steep, $\sim 40^{\circ}$ slopes and effective cohesive strength was provided by a root network. The observations indicate that fractured bedrock channelized the infiltrating flow towards the hollow and caused localized seepage into the overlying soil mantle, elevating pore pressures artesianally in one region to failure and subsequently creating a larger scale failure. The measured pore pressure, reported as its ratio to the overlying soil thickness times the unit weight of water (the peak value of which was 0.75 and coincided near a presumed initiating region), did not reach the local slope-normal stress (corresponding approximately to a ratio of 1 for the nominal slope angle and typical bulk soil weight). Furthermore, the pore pressures over what would eventually be the failure surface were generally much less than the peak value.

With respect to the scenarios above, we will explore whether a slipping region may be brought to the point of unforced propagation before pore pressures reach the total slope-normal stress. Perhaps not unexpectedly, in the model examined below we will find that this is largely dependent on the distribution of pressures, and particularly, how locally peaked the distribution is. This line of work parallels that of others, who, in the interest of studying artificially induced dynamic rupture nucleation on faults with slip-weakening [Garagash et al., 2009; Garagash and Germanovich, 2011] or rate-and-state friction [McClure and Horne, 2010], examined the effect of the along-fault diffusion of an in-plane point source of constant pore pressure or fluid flux. Indeed, in some of what will follow in Section 4 (particularly, ruptures far from a free surface) we take, as a starting point for landslide representation, conditions that are comparable to those for buried earth faults. First, however, we will consider in Section 2 conditions by which ambient pore pressures may be elevated near the point of failure, focusing on the sedimentation of submarine slopes; and in Section 3 we will look for sources of perturbations to the elevated pore pressure sufficient to initiate sliding.

\section{Steady, long-time sedimentation with consolidation and effective-stress-dependent permeability}

Given typical sedimentation rates and sediment permeabilities, pore fluid pressures beyond hydrostatic are expected and are often observed in the field [e.g., Flemings et al., 2008]. These results generally show conditions of high pore fluid pressures with depth, often with the vertical profile near to and paralleling that of total sediment weight. That effective stress may thereby become nearly independent of depth is of interest for slope stability. Particularly, while shear stress may increase with depth, frictional strength may remain approximately constant. Therefore, there is an interest in determining how shallowly this overpressure begins and what is its magnitude. In the following, we perform a simplified consolidation-sedimentation analysis to estimate near-seafloor conditions.

We assume that the solid sediment particles and pore fluid are much less compressible than the sediment matrix under drained conditions, and that all compaction occurs in the downward, slope-perpendicular direction, $z$. Where $q$ is the flux of pore fluid in the sediment and $\epsilon$ is the slopeperpendicular extensional strain, the conservation of fluid mass reduces to a conservation of fluid volume

$$
\frac{\partial q(z, t)}{\partial z}+\frac{\partial \epsilon(z, t)}{\partial t}=0
$$

Additionally, the compaction rate of the sediment matrix is proportional to the rate of the effective stress $\sigma^{\prime}(z, t)$ (positive in compression),

$$
\frac{\partial \epsilon(z, t)}{\partial t}=-m_{v} \frac{\partial[\sigma(z, t)-u(z, t)]}{\partial t}
$$

where $\sigma(z, t)$ is the total normal stress, $u(z, t)=p(z, t)-$ $p_{h}(z)$ is the pore pressure in excess of hydrostatic, and $m_{v}$ is the compressibility of the sediment under 1D consolidation conditions (strain only in $z$ ). Finally, the fluid flux $q$ is assumed to follow Darcy's law $q(z, t)=-\left(k / \mu_{f}\right) \partial u(z, t) / \partial z$, where $k$ is the permeability of the sediment (initially assumed constant here), and $\mu_{f}$ is the viscosity of the permeating fluid. Combining the above equations, we arrive to

$$
c_{v} \frac{\partial^{2} u(z, t)}{\partial z^{2}}=-\frac{\partial[\sigma(z, t)-u(z, t)]}{\partial t}
$$

where $c_{v} \equiv k / \mu_{f} m_{v}$ is the hydraulic diffusivity.

Considering the moving-boundary problem of seafloor that aggrades uniformly with a sedimentation rate $R_{s}$, we take time derivatives in a co-moving reference, where the origin of the coordinate $z$ rises with the seafloor. Specifically, we replace $\partial[\sigma(z, t)-u(z, t)] / \partial t$ above with $D[\sigma(z, t)-$ $p(z, t)] / D t$ where $D(\cdot) / D t=\partial(\cdot) / \partial t-R_{s} \partial(\cdot) / \partial z$. Looking for steady-state solutions under constant sedimentation $R_{s}$, such that local time derivatives vanish, the above reduces to an ordinary differential equation

$$
c_{v} \frac{d^{2} u(z)}{d z^{2}}+R_{s} \frac{d u(z)}{d z}=R_{s} \gamma
$$


where $R_{s} \partial\left(\sigma-p_{h}\right) / \partial z=R_{s} \gamma$ and $\gamma=\left(\gamma_{b}-\gamma_{w}\right) \cos \theta$ is the slope-perpendicular component of the buoyant weight, where $\gamma_{b}=\rho_{b} g$ is the specific weight of sediment with bulk density $\rho_{b}$ under gravity $g$ (typically, $\gamma_{b} \approx 1.5-2 \gamma_{w}$, with $\gamma_{w}$ the specific weight of water). The general solution satisifying $u=0$ at $z=0$ is

$$
u(z)=\gamma z-C \frac{c_{v} \gamma}{R_{s}}\left[1-\exp \left(-R_{s} z / c_{v}\right)\right]
$$

where $0 \leq C \leq 1$ is a constant chosen to satisfy an imposed condition $\gamma \geq d u(0) / d z \geq 0$. For a hydrostatic pore pressure gradient as $\bar{z}$ approaches the seafloor, $C=1$.

The above may be considered as a long-time solution of the steady sedimentation problem treated by Gibson [1958]
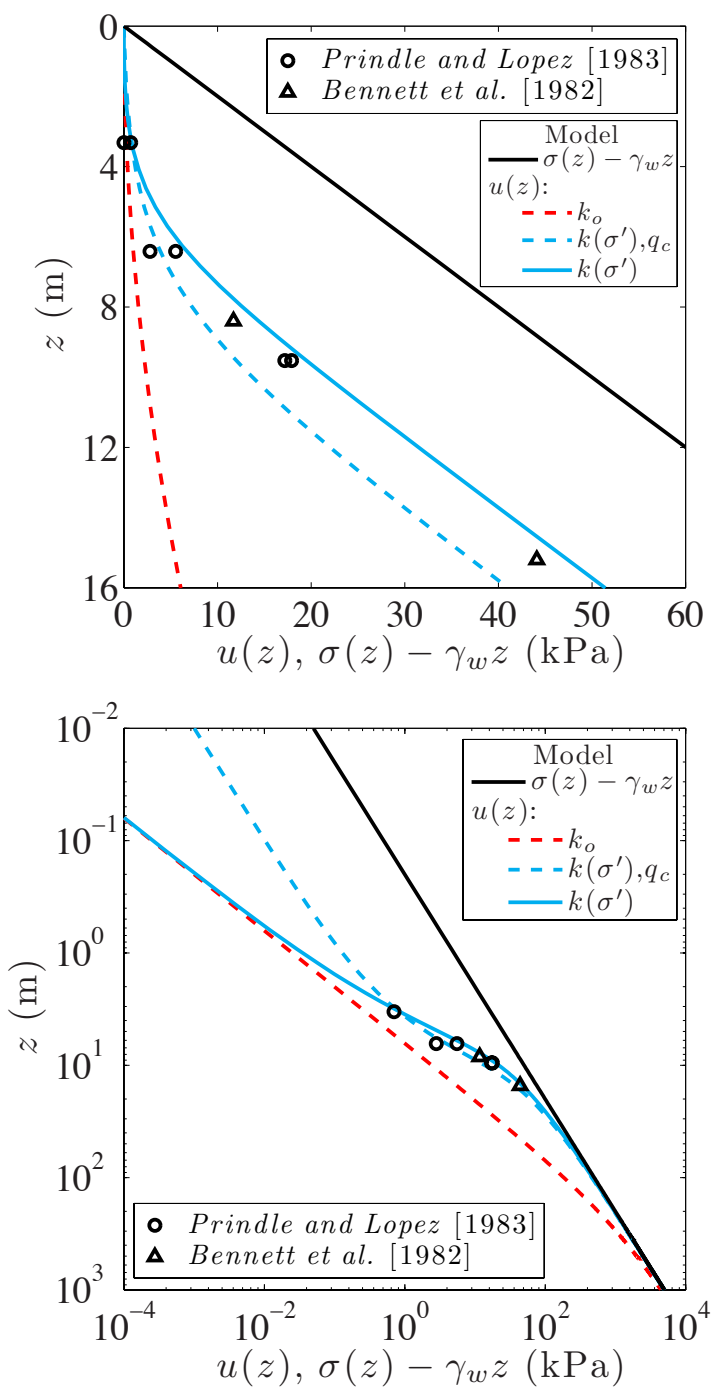

Figure 1. Comparison of pore pressure in excess of hydrostatic, $u(z)$, determined by separate measurements on the southern shelf of the Mississippi delta (points) and by models representing steady sedimentation (colored lines). Models treat permeability either as a constant (dashed red) or as an exponentially decreasing function of effective stress (blue). Two of the models are direct solutions of steady sedimentation-consolidation problems with a hydrostatic pore-pressure gradient at the seafloor while the third (dashed blue) is the solution to a problem of constant flow $q_{c}$ (hence its departure at shallow depths). Total normal stress of model (black) plotted for comparison. (i.e., the base of the sedimentary basin is considered much farther than the depths of interest). The above result would suggest that the effective stress $\sigma^{\prime}(z)=\gamma z-u(z)$ becomes constant at a depth of the order $c_{v} / R_{s}$, beyond which the pore pressure follows lithostatic stress. However for typical sedimentation rates $\left(R_{s}=0.01-10 \mathrm{~mm} / \mathrm{yr}\right)$ and diffusivities $\left(c_{v}=10^{-6}\right.$ to $10^{-8} \mathrm{~m}^{2} / \mathrm{s}$, smaller values typical for deeper sediments) of fine-grained submarine sediments, that depth to constant effective stress (and consequently, constant strength) has a great range of values of depths (nearly all $>100 \mathrm{~m}$ ). That would exclude the possibility of sedimentation-induced overpressure generating landslides (typically at depths $<100 \mathrm{~m}$ ).

As an improvement on the above, we no longer assume a constant, depth-independent diffusivity and account for an acute effective-stress dependence of permeability. Specifically, the Darcy relation above is now written as

$$
q(z, t)=-\frac{k\left[\sigma^{\prime}(z, t)\right]}{\mu} \frac{\partial u(z, t)}{\partial z}
$$

where here we take $k\left(\sigma^{\prime}\right)=k_{o} \exp \left(-\sigma^{\prime} / \sigma^{*}\right)$, where $k_{o}$ is the permeability at the seafloor, and $\sigma^{*}$ is a parameter that sets the sensitivity to effective stress. Indications are that $\sigma^{*}=0.1-0.5 \mathrm{MPa}$ for sediments from 30-70 m below the seafloor to a few $100 \mathrm{~m}$ below [Henry, 2000; Long et al., 2008] and damaged basin fault zones at $\mathrm{km}$ depth [Revil and Cathles, 2002], and $\sigma^{*}=6 \mathrm{MPa}$ for sediments at basin-scale depths $(>1 \mathrm{~km})$ [Tanikawa et al., 2008].

In this case, the equation governing the excess pore pressure resembles that above, now with additional nonlinear terms moderated by the nondimensional group $A \equiv$ $c_{v}^{o} \gamma / R_{s} \sigma^{*}$, which compares typical near-seafloor pressures to the stress-senstivity of the permeability, and for which $c_{v}^{o} \equiv k_{o} / \mu m_{v}$. Solving the equation numerically for increasing values of $A$, the depth to constant effective stress is reduced when compared to the previous assumption of constant permeability (when $c_{v}$ of the constant permeability case corresponds to $c_{v}^{o}$ for comparison).

As a simple case study, we consider a shallow-water $(\sim 20$ $m$ ) location on the southern shelf of the Mississippi River delta that was the site of two independent sets of pore pressure measurements within six years and a few hundred meters of each other [Bennett et al., 1982; Prindle and Lopez, 1983]. The trend of the observations is for the pore pressure to track the lithostatic stress beginning at a depth of approximately $6 \mathrm{~m}$ (Figure 1). Assuming a hydrostatic pore pressure gradient at the seafloor, we find good agreement with the observations and the model posed by (??) taking $\gamma=0.5 \gamma_{w}, c_{v}^{o}=10^{-7} \mathrm{~m}^{2} / \mathrm{s}, \sigma^{*}=0.01 \mathrm{MPa}$, and $R_{s}=10^{-9}$ $\mathrm{m} / \mathrm{s}(\sim 30 \mathrm{~mm} / \mathrm{yr})$, which is of the order of rates measured in regions of the shallow western shelf [Corbett et al., 2006]. The data is not well fit by the solution (7) for permeability fixed at the seafloor value $k_{o}$ (Figure 1), neither when allowing for a variation from the material properties and rates chosen above (not shown). Interestingly, the $\sigma^{*}$ used here for the upper $20 \mathrm{~m}$ of near-shore sediments is an order smaller than that suggested for accretionary prism sediments at depths of several hundred meters and basin sediments on the Gulf of Mexico continental slope. While the inference of $\sigma^{*}$ from the shallow pore pressure data may seem anomalous, perhaps due to the unaccounted for presence of biogenic gas, its order of magnitude is consistent with studies on terrestial clays. Potts et al. [1997] arrange a compilation of prior laboratory and field tests on the overconsolidated London and Upper Lias clays as a plot of permeability with depth showing a three order of magnitude change over $20 \mathrm{~m}$. Assuming the effective-stress gradient at the past maximum pressure to be anywhere from hydrostatic $\left(\gamma_{w}\right)$ to lithostatic $\left(2 \gamma_{w}\right)$ and, as a coarse estimate, 


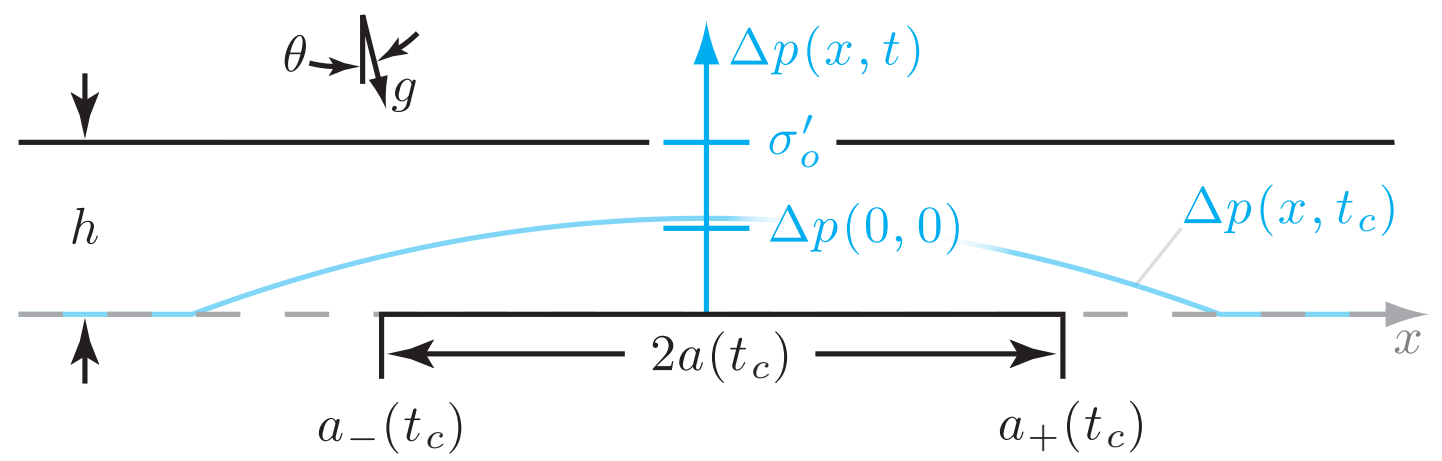

Figure 2. Superposition of a peaked pore pressure profile along a depth $h$ (blue) on an illustration of a slipping region that parallels a slope surface (both black). The profile shown corresponds precisely to that which would generate the illustrated slipping region. The slipping region is enlarged by a gradual increase of pore pressure $\Delta p(x, t)$ to a critical extent, illustrated here at $t=t_{c}$, beyond which its growth may continue without any further pressure increase. The value $\Delta p(0,0)=\sigma_{o}^{\prime}-\tau_{o} / f_{p}$ is that at which a failure criterion is first met and sliding is initiated at the origin. A frictional length scale $\ell$ is used to denote relative depth by $H \equiv \sqrt{h / \ell}$. Here $\tau_{o} / \sigma_{o}^{\prime}=0.25$ and $f_{p}=0.5$ (i.e., $\Delta p(0,0)=0.5 \sigma_{o}^{\prime}$ ), $H=0.5$, and $K_{h \ell}=1$ is the dimensionless profile curvature defined in text. Interestingly, in the case considered here, only a marginal increase past $\Delta p(0,0)$ is required to bring the slope to the critical point.

that past unloading and weathering resulted in negligible change in the gradient of permeability with depth, yields $\sigma^{*}=0.03-0.06 \mathrm{MPa}$.

A solution approximate to this steady-sedimentation model could have been arrived at analytically by examining the case of steady seafloor-driven flow $q_{c}$ (positive towards the seafloor) under a permeability that decreased exponentially with effective stress. Under these conditions

$$
q_{c}=\frac{k\left[\sigma^{\prime}(z)\right]}{\mu} \frac{d u(z)}{d z}=-\frac{k\left[\sigma^{\prime}(z)\right]}{\mu}\left(\frac{d \sigma^{\prime}(z)}{d z}-\gamma\right)
$$

which is an ordinary differential equation for $\sigma^{\prime}$ whose nondimensional solution [Rice, 1992] is

$$
u(z)=\gamma z+\sigma^{*} \ln \left[\alpha+(1-\alpha) \exp \left(-\gamma z / \sigma^{*}\right)\right]
$$

where $\alpha=q_{c} \mu /\left(\gamma k_{o}\right)$. For $\sigma^{*}=0.01 \mathrm{MPa}$ and $\alpha=1 / 50$ we find a reasonable approximation to the steady-sedimentation solution in Figure 1. For $\mu_{f} \approx 10^{-3} \mathrm{~Pa} \cdot \mathrm{s}, k_{o}=10^{-15} \mathrm{~m}^{2}$, and $\gamma=0.5 \gamma_{w}$, this implies $q_{c}=R_{s} / 10 \approx 3 \mathrm{~mm} / \mathrm{yr}$ for the high sedimentation rate $R_{s}$ chosen for steady sedimentation solutions in Figure 1. This flow rate is not unreasonable for the regime and may be an a posteriori choice.

Using the two-dimensional model of steady sedimentation with consolidation, we estimate conditions on the continental slope. We assume a slightly lower sedimentation rate, but choose a value that is relatively high for continental slope sites, $R=10 \mathrm{~mm} / \mathrm{yr}$. We assume a range of possible seafloor values of the coefficient of consolidation, $c_{v}^{o}=10^{-5}$ to $10^{-8} \mathrm{~m}^{2} / \mathrm{s}$, and a conservative $\sigma^{*}=0.25 \mathrm{MPa}$. We calculate the steady pore pressure distribution with depth, $p(z)=\gamma_{w} z+u(z)$ with $u(z)$ being the solution to (??); and we estimate a factor of safety that is the ratio of a frictional strength (taken as $\tau_{\max }(z)=f_{p}[\sigma(z)-p(z)]$ with $f_{p}=0.5$ ) to the shear stress $\tau(z)=\left(\gamma_{b}-\gamma_{w}\right) \sin \theta$. The shallowest depth to failure of a $4^{\circ}$ slope is approximately $100 \mathrm{~m}$ (taking $\gamma_{b}-\gamma_{w}=10 \mathrm{kPa}$ in this depth range) with the factor of safety being as low as 2 for half the depth of failure. While the depth of failure is shallower than predicted by a constant-permeability model using the near-seafloor permeability alone, it is comparatively deep relative to commonly observed landslides and would require long periods of high $(10 \mathrm{~mm} / \mathrm{yr})$ sedimentation. This indicates that even with efficient overpressure by permeability reduction, failure of sediments on continental slopes by fast sedimentation alone may not be likely. In the subsequent section, we examine how perturbations to such elevated pore pressures may create a local failure.

\section{Sources of local increases in pore pressure on seafloor}

Localized pore pressures near the seafloor may be brought about by high-permeability pathways that facilitate the drainage of a compacting basin. The pathways may take the form of faults [e.g., Screaton et al., 2000], or even inclined coarse-grained turbidite deposits on buried paleocanyons, and are often expressed as depressions on the seafloor [e.g., Gay et al., 2007]. Dugan and Flemings [2000] quantify potential pore pressure changes with a twodimensional sedimentation-consolidation calculation of a nonuniform sedimentation scenario. A resulting high permeability conduit may elevate near-seafloor pore pressures to lithostatic stresses at a site with known failures. Such channelized flow may sufficiently elevate pore pressures to create liquefied sediments, like those retrieved from a deepwater core of a pockmark above an apparent fluid chimney [Gay et al., 2006]. In this instance, the $800 \mathrm{~m}$-wide pockmark appeared on seismic data as the seafloor expression of a vertical fluid seep rooted in a buried paleochannel. The pore pressure path followed by the buoyant rise of fluids pressurized at depth would likely meet liquefaction conditions well below the seafloor, as shown by surface and subsurface disturbances induced by biogenic or thermogenic gas seeps [e.g., Pinet et al., 2008].

Methane hydrates may present an alternative source of quasi-statically elevated pore pressures. Implications in landsliding are driven by the coincidence of some continental slope landslide regions with gas hydrate [e.g., Kayen and Lee, 1991]. The pore pressures may come directly from hydrate decomposition, or by indirect pressurization. The excess pore pressures generated by hydrate dissociation are generally large, even when considering fluid flux and finite dissociation rates. Dissociation at the base of the stability zone by sedimentation burial, uplift, or sealevel drop, may be more than sufficient to meet a shear-strength criterion [Xu and Germanovich, 2006]. However, the base of the stability zone is often greater than $200 \mathrm{~m}$ below the seafloor [Haacke et al., 2007], and would imply relatively deep-seated large landslides. More favorably to landsliding, gas plumes may indicate hydrate decomposition at shallower depths along the upslope stability limit [Westbrook et al., 2009]. However, the pore pressure calculations of $X u$ and Germanovich [2006] indicate that levels may even exceed 
lithostatic stresses, which may create features of vertical fluid expulsion or sediment disturbance, like those observed in seismic data by Berndt et al. [2005] over lengths of 1-10 $\mathrm{km}$ coinciding with a landslide scarp. They propose that high dissociation rates accompanying the rapid erosion resulted in observed subsidence by fluid expulsion with fluidization of a finite thickness of overlying sediments, implying that pore pressures were elevated near lithostatic stresses at least $50-100 \mathrm{~m}$ above the dissociated region over kilometer lengthscales. The loss of matrix support by hydrate dissolution or decomposition, and subsequent underconsolidation, has also been proposed to elevate pore pressures broadly at the stability base [Kvenvolden, 1993]. Sultan et al. [2010] advocated similar underconsolidation at shallower depths to explain the apparent progression of pockmark formation through observed morphological stages; there underconsolidation was presumed result from focused flow from depth carrying a transient supply of methane that stimulated first hydrate growth before dissolution.

The overpressure by gas accumulation at the base of the stability zone has often been cited as being sufficient to drive an invasive flow to the seafloor expressed as seafloor pockmarks and pipes [Bünz et al., 2003; Flemings et al., 2003; Gay et al., 2007; Liu and Flemings, 2007; Cathles et al., 2010], as well as by conduits created by induced normal faulting [Hornbach et al., 2004]. The elevated pore pressures en route to the surface may be sufficient to create liquefied sediments, like that for the cold seeps discussed above (as in the formation of pockmarks). Pockmark size can then be an indication of pore pressure distributions (whether sourced in hydrates or not) and range from a few tens of meters [e.g., in shallow water; Andrews et al., 2010] to kilometer lengthscales [e.g., on the continental slope; Sultan et al., 2010].

\section{Rupture nucleation by local increases in pore pressure}

In this section we investigate the growth of a slipping rupture in response to local elevations in pore pressure. Slip is presumed to start at a depth $z=h$ (in the coordinate of Section 2), along a surface running parallel to the seafloor or Earth's surface (Figure 2). The mode of failure examined here is solely the accumulation and propagation of slip: i.e., we do not consider additional modes as might occur, for instance, at pore pressures approaching the total overburden. Here, the failure surface is predetermined, as may be dictated by natural stratification or boundaries. The shear strength, $\tau_{\max }$ of the slip surface is assumed to be purely frictional

$$
\tau_{\max }=f[\delta(x, t)][\sigma(x, t)-p(x, t)]
$$

where $\sigma(x, t)$ and $p(x, t)$ are the total slope-normal stress and pore pressure along the slip surface and $f$ is a friction coefficient taken as dependent on the local slip of the surface, $\delta(x, t)$. In all sections we will presume that the friction coefficient weakens with slip. In 4.1 we examine a small-slip case where a residual level of friction is not yet reached. There we show that growth of the slip surface transitions from a quasistatic growth forced by pore pressure to an unforced, dynamic growth. In 4.2 and 4.3 we include the possibility of reaching a residual friction and show that this may lead to the arrest of dynamic rupture growth (as also demonstrated by Garagash and Germanovich [2011]). In these preceding subections we presume that the rupture occurs far from the free surface and in 4.4 we show that accounting for its proximity leads to a transition in nucleation behavior between deep and shallow limits.

Before local pore pressure increases begin, we assume that there is a constant shear stress $\tau_{o}$, total normal stress $\sigma_{o}$ (positive in compression), and pore pressure $p_{o}$ acting along the depth of the future slip surface. The shear and total normal stress may be those of an infinite slope and in the submarine case, the initial pore pressure may correspond to that calculated in Section 2 at a particular depth $z=h$. The initial effective normal stress is then $\sigma_{o}^{\prime}=\sigma_{o}-p_{o}$.

Given the variety of means to increase pore pressures, as a first step we simplify the form that a pore pressure increase takes. The purpose is to isolate the first-order characteristics, namely, the magnitude of the increase and its distribution in space. The simplified distribution is locally peaked and increases uniformly in space at a constant rate $R$. The amount the pore pressure falls with distance from the peak is given by a function $q(x)$. The pore pressure begins to elevate from $p_{o}$ and we are first interested at the point of time when slip is initiated. For a peak friction coefficient $f_{p}$, failure will first occur when $\Delta p=\sigma_{o}^{\prime}-\tau_{o} / f_{p}$. We take this point in time to be $t=0$. This defines the pore pressure increase as

$$
\Delta p(x, t)=\left[\sigma_{o}^{\prime}-\tau_{o} / f_{p}\right]+R t-q(x)
$$

at $x$ for which (12) is positive, with $\Delta p(x, t)=0$ otherwise. We take a simple symmetric function $q(x)=\kappa x^{2} / 2$ whose single parameter $\kappa>0$ is the sharpness of the pore pressure increase. The peak magnitude of the pore pressure is given by the nondimensional parameter

$$
T \equiv \frac{f_{p}}{\tau_{o}} R t
$$

$T=0$ when slip initiates at $t=0($ and $x=0)$ and $T=1$ some time later when the pore pressure reaches the total slope-normal stress $\left(p=\sigma_{o}\right)$ at $x=0$.

For failure to initiate at a depth $20 \mathrm{~m}$ below the seafloor of a $2^{\circ}$ slope under initially hydrostatic conditions, the point of first failure $(T=0)$ corresponds to a pore pressure increase of approximately $93 \mathrm{KPa}$. This increase represents $93 \%$ of the effective initial overburden $(100 \mathrm{KPa}$, corresponding to $T=1$ ). For comparison, for failure to initiate at a depth $5 \mathrm{~m}$ below the earth surface of a $20^{\circ}$ slope under dry, subaerial conditions, point of first failure corresponds to a pore pressure of $25 \mathrm{KPa}(T=0)$, representing $\sim 25 \%$ of the slopenormal stress (95 $\mathrm{KPa}, T=1)$.

We take the friction coefficient at a point on that surface to weaken linearly with slip $\delta$ from a peak value $f_{p}$ to a residual value $f_{r}$ after slipping an amount $\delta_{c}$. For slip $\delta<\delta_{c}$

$$
f(\delta)=f_{p}-w \delta
$$

where $w=\left(f_{p}-f_{r}\right) / \delta_{c}$. The dimensionless variable for slip is $\bar{\delta} \equiv \delta w / f_{p}$, which may range between 0 when $f=f_{p}$ and 1 when $f=0$ (the lowest possible value for $f_{r}$ ). For overconsolidated sediments, $f_{p}, f_{r}$, and $\delta_{c}$ may be estimated from the ring shear experiments of Bishop et al. [1971]. For the London Brown and Blue Clays sampled, friction drops from $f_{p}=0.45$ to $f_{r}=0.2-0.25$. The friction coefficient does not strictly follow a linear drop to residual value, but the initial linear slip-weakening rates are $w=0.08-0.3 / \mathrm{cm}$. Normally consolidated sediments may also weaken with slip and have comparable weakening rates. This is the case if we presume that the initial decrease in friction of 1) an aged, normally consolidated soil is comparable to the decrease in friction of 2) an overconsolidated clay that has a) been sheared to a residual friction and b) been allowed to regain some strength under fixed displacement. While the strength gain is time dependent, for experiments on 2) with healing times of 100-200 days the drop in friction coefficient with slip is low $\left(f_{p}-f_{r} \approx 0.05\right)$, but occurs over smaller displacements, with initial slip-weakening rates in the range $w=0.3-0.8 / \mathrm{cm}[$ Stark et al., 2005; Carrubba and Del Fabro, 

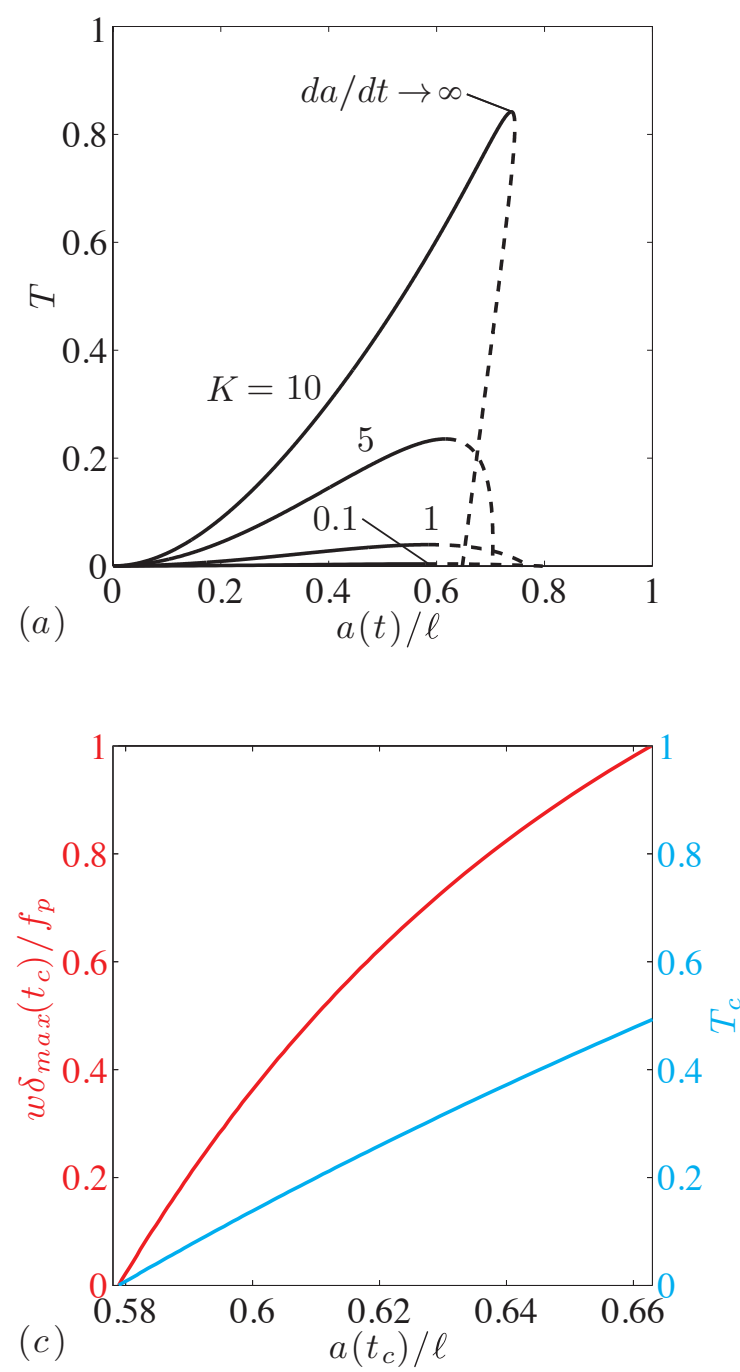
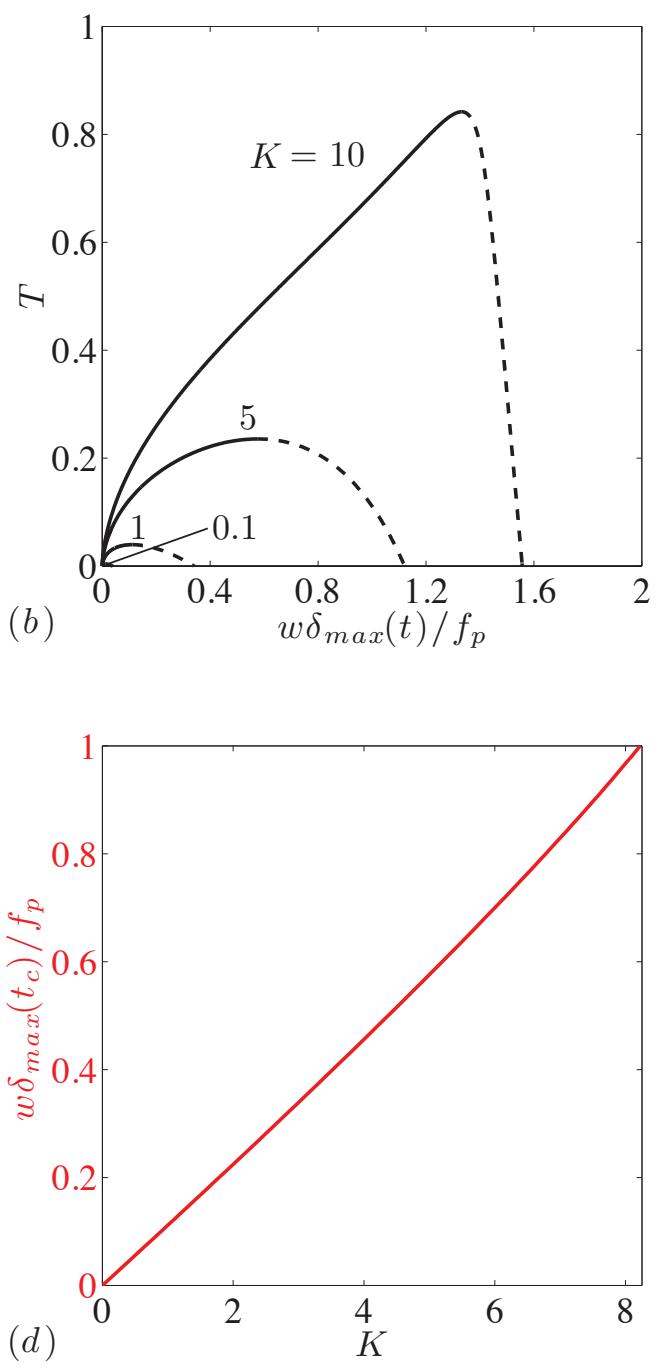

Figure 3. (a) Enlargement of crack length $a(t)$ with increasing pore pressure $R t$, nondimensionally as $\mathrm{T}$, for profiles of pore pressure with various curvatures $\kappa$, nondimensionally as $K$. (b) Plot of maximum slip $\delta_{\max }(t)$, occuring at $x=0$, against pore pressure increase. The nucleation of a dynamic rupture occurs at the peak of the loading paths and the crack propagates without any further increase in pore pressure. (c) Plot of peak slip (red) and pore pressure increase (blue) against the crack length at the point of nucleation. (d) Plot of peak slip at nucleation against the nondimensional profile curvature. These analyses assume that $f_{r} / f_{p}<\left(1-w \delta_{\max } / f_{p}\right)$, implying that solutions with $w \delta_{\max } / f_{p}>1$ are unphysical.

2008; and Stark and Hussain, 2010]. A freshly sedimented seafloor, like that presented in Section 2 with accumulation rates of the order of $1 \mathrm{~mm} / \mathrm{yr}$, would represent a potentially well aged, normally consolidated slope. However, if erosion and prior landslide events remove material, then the uncovered seafloor will be effectively overconsolidated.

The slip weakening introduces a length scale

$$
\ell^{*} \equiv \frac{\mu^{*}}{\sigma_{o}^{\prime} w} \equiv \frac{\mu^{*} \delta_{c}}{\tau_{p}-\tau_{r}}
$$

like that in (2), where here $\tau_{p / r}=f_{p / r} \sigma_{o}^{\prime}$ are nominal peak and residual strengths. We estimate $\ell^{*}$ under two conditions: a subaerial slope and a submarine one. In subaerial conditions, we presume failure occurs $5 \mathrm{~m}$ below the surface and estimate the initial effective normal stress as that of an infinite slope, $\sigma_{o}^{\prime}=\gamma_{b} z \cos \theta$, with a slope of $\theta=20^{\circ}$, and a typical sediment unit weight $\gamma_{b} \approx 2 \gamma_{w}$. For submarine conditions, we presume failure occurs $20 \mathrm{~m}$ below the seafloor and take hydrostatic conditions where $\sigma_{o}^{\prime}=\left(\gamma_{b}-\gamma_{w}\right) z \cos \theta$, with a slope of $\theta=3^{\circ}$, and the sediment unit weight $\gamma_{b} \approx 1.5 \gamma_{w}$. The sediment's elastic stiffness is perhaps the most variable quantity, and we consider that the shear modulus $\mu$ may range between $10-100$ MPa, with $\nu=1 / 3$ (corresponding to shear wave speeds of a few hundred meters per second; and $\mu^{*}=15-150 \mathrm{MPa}$ for mode-II deformation). For both environments, we take an intermediate value for the slip weakening rate $w=0.5 / \mathrm{cm}$. This yields similar estimates for $\ell^{*}: \ell^{*}=3.2-32 \mathrm{~m}$ for subaerial conditions, and $\ell^{*}=3-30 \mathrm{~m}$ for submarine conditions.

\subsection{Nucleation far from a free surface}

Here we assume that the slipping length at nucleation is much shorter than the depth $h$ below the free surface. In this case, the shear stress along the plane of the slip surface is, for a linearly elastic material [e.g., Bilby and Eshelby, 1968],

$$
\tau(x, t)=\tau_{o}-\frac{\mu^{*}}{2 \pi} \int_{a_{-}(t)}^{a_{+}(t)} \frac{\partial \delta(\xi, t) / \partial \xi}{x-\xi} d \xi
$$


where $a_{+}$and $a_{-}$are the endpoints of the slipping region (Figure 2). Over the slipping region this shear stress must meet the strength requirement

$$
\tau(x, t)=\left[f_{p}-w \delta(x, t)\right]\left[\sigma_{o}^{\prime}-\Delta p(x, t)\right]
$$

with the prefactor replaced by $f_{r}$ once slip exceeds $\delta_{c}$. In this subsection we will assume that $f_{r}$ is not yet engaged and will address this case in the following subsection.

In this "deep" context and for profiles of this type, a more convenient lengthscale is

$$
\ell \equiv \ell^{*} \frac{\tau_{p}}{\tau_{o}} \equiv \frac{f_{p} \mu^{*}}{\tau_{o} w}
$$

The ratio $\ell / \ell^{*}$ can be estimated assuming infinite slope conditions where either $\tau_{o} / \sigma_{o}^{\prime}>\tan \theta$ when pore pressure is in excess of hydrostatic or $\tau_{o} / \sigma_{o}^{\prime}=\tan \theta$ for "dry" subaerial slopes or submerged slopes with hydrostatic pressure distributions. For the last set of cases and $f_{p}=0.5$, $\tau_{o} / \tau_{p} \approx 0.07-0.7$ for $\theta=2-20^{\circ}$, meaning that $\ell$ for lowangle, deepwater continental slopes is an order larger than that for steeper subaerial counterparts.

It is the length $\ell$ with which rupture tip lengths are accordingly nondimensionalized to an average length $\bar{a}(t) \equiv$ $\left[a_{+}(t)-a_{-}(t)\right] / 2 \ell$, with an asymmetry measure $\bar{b}(t) \equiv$ $\left[a_{+}(t)+a_{-}(t)\right] / 2 \ell$, and also with which distance is normalized to $\bar{x}_{o} \equiv x / \ell-\bar{b}(t)$. For the symmetric increase (12), $b(t)=0$

The curvature of the pore pressure nondimensionalizes to

$$
K \equiv \frac{f_{p}}{\tau_{o}} \kappa \ell^{2}
$$

The convenience of the above scaling is that the profile is solely described by parameters $T$ and $K$, so long as the endpoints of the crack are within the curved portion of the pore pressure profile (as in Figure 2). This is reasonably assumed to be the case in this subsection. (Another parameter, $\tau_{o} / \tau_{p} \equiv \tau_{o} /\left(f_{p} \sigma_{o}^{\prime}\right)$, determines the location where $\Delta p(x, t)=0$.)

For a given curvature $K$, the slip distribution is solved at each stage of the pore pressure increase $(T)$ using a GaussChebyshev quadrature collocation technique (Appendix B). The peak slip (located at the crack center for this symmetric loading scenario) and crack length are presented in Figure 3. Each path corresponds to a pore pressure increase with a fixed curvature. A common feature of all the paths is the tendency for greater growth of the crack half-length $a(t)$ and peak slip $\delta_{\max (t)}$ in response to a given increment of the pore pressure as the increase progresses. Eventually a point is reached where the growth rates of these quantities are unbounded (and continuation of the quasi-static solutions requires a decrease in pore pressure). Where the rates become unbounded (a time labeled $t=t_{c}$ ) marks the onset of the nucleation of dynamic rupture: i.e., once the pore pressure reaches the peak levels in Figure 3, rupture may continue to propagate as an accelerating rupture, without any further increase in pore pressure, driven by frictional weakening. The elastodynamic ruptures are expected to accelerate to a limiting speed of the order of the shear-wave speed (for sediments, typically of the order of $100 \mathrm{~m} / \mathrm{s}$ ).

In the limit of very broad curvatures $(K \rightarrow 0)$, the quasistatic problem reduces to an eigenvalue problem like that of Uenishi and Rice [2003]. The limit of the eigenvalue problem $\left(a\left(t_{c}\right) / \ell \approx 0.579\right.$; Appendix $\left.\mathrm{A} 1\right)$ is met by the numerical solutions for small $K$. Such broad curvatures induce sliding over a large region for only small increases in pore pressure past that which would first start sliding at the origin $(T=0)$, and the critical increase $T_{c}$ and peak slip $\delta_{\max }\left(t_{c}\right)$ are very small. In contrast are the sharper loading profiles $K=1,5$ that require more substantial pore pressure increases to reach the point of nucleation, accumulating much more slip in the process.

We recall that slip is nondimensionalized such that the friction coefficient is $f=(1-\bar{\delta}) f_{p}$. At the nucleation point corresponding to the case $K=5$ in Figure 3, the friction coefficient at the center of the crack has been reduced to
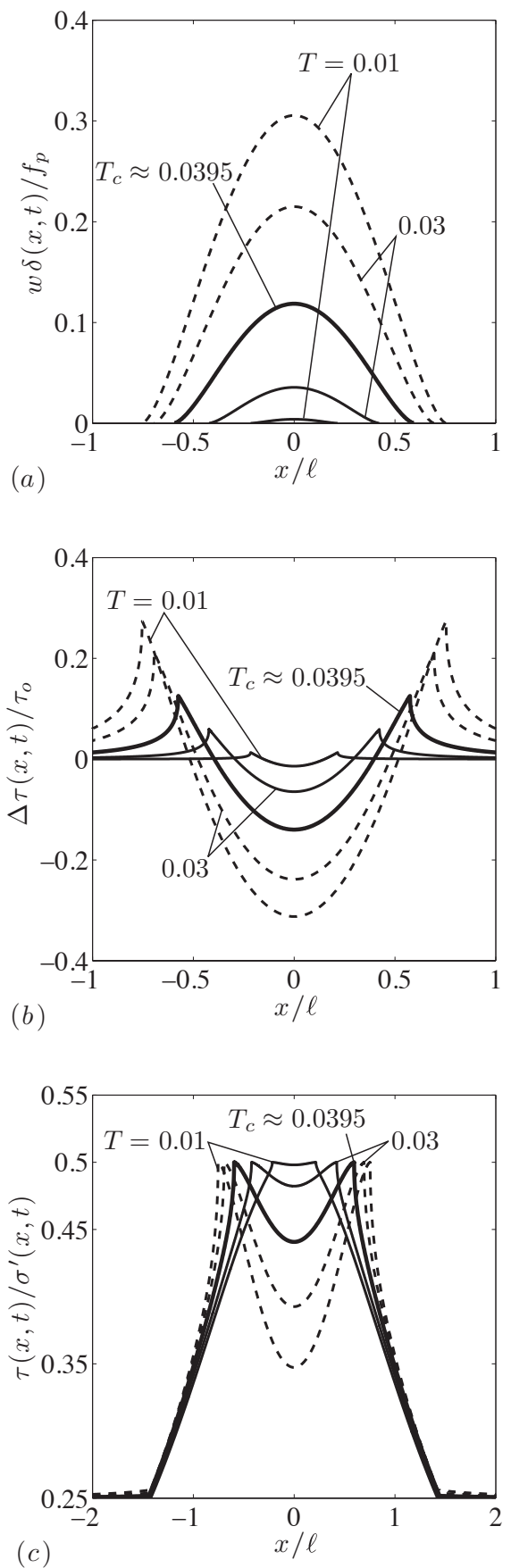

Figure 4. Distribution of (a) slip and (b) shear stress change for various levels of pore pressure increase $T \equiv$ $R t f_{p} / \tau_{o}$ and fixed curvature $K \equiv f_{p} \kappa \ell^{2} / \tau_{o}=1$. (c) Ratio of shear stress to effective normal stress for $f_{p}=0.5$ and $\tau_{o} / \sigma_{o}^{\prime}=0.25$. Solid curves are those distributions originating from a nucleated crack of zero length to an unstable limit (bold), dashed curves are unstable distributions beyond the point of nucleation. 

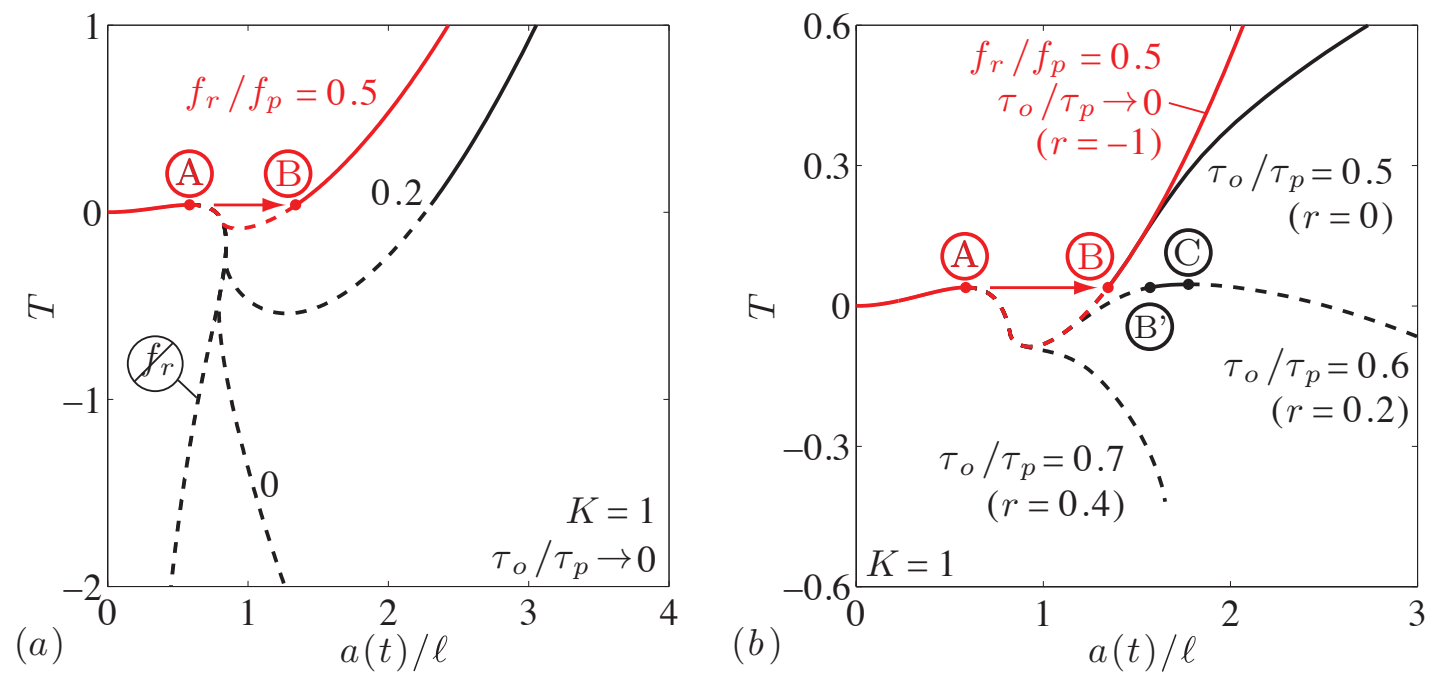

Figure 5. Solutions of crack length $a(t)$ with increase in pore pressure $T$ at a fixed curvature $K=1$. Solid and dashed lines represent stable and unstable quasistatic solutions. (a) Solutions for variable $f_{r} / f_{p}$, and the solution neglecting residual friction. In these solutions the shear stress is small (low $\left.\tau_{o} / \tau_{p}\right)$. Starting with the solution of (a), $f_{r} / f_{p}=0.5$ (red), the solutions in (b) show the result of increasing shear stress $\tau_{o} / \tau_{p}$ (black).

$f \approx 0.4 f_{p}$. For the loading history corresponding to the sharper profile $(K=10)$, we see that so much slip accumulates that nucleation ultimately occurs for $\bar{\delta}_{\max }>1$, and the result can be dismissed as an unphysical representation (i.e., $f<0$ ). However, had we imposed a residual friction, say $f_{r} / f_{p}=0.2$, on the case $K=10$, pore pressures reach the total slope-normal stress $(T=1)$ before nucleation occurs (case not shown). Therefore, determining the relative sharpness of a profile is important for determining if modes of failure other than pure slip can be expected (i.e., if $T=1$ is reached), as well as the total amount of slip before dynamic rupture. Figures $3 \mathrm{c}, \mathrm{d}$ show conditions at nucleation over a broad range of curvatures. Most remarkably, the critical length at nucleation is relatively insensitive to the profile curvature, although the accrued slip may vary widely. We note here that the slope angle is subsumed in the definition of $K$ (implicitly, via $\tau_{o}$ ). As a result, $K \sim 1 / \sin ^{3} \theta$, implying that shallow slopes are more likely to have a large $K$ for a wide range of dimensional curvatures $\kappa$.

Figure 4 takes snapshots along the depth $z=h$ at fixed points in time for the load path of the case $K=1$ of Figure 3. Figure 4a shows the distribution of slip up to the point of nucleation (solid lines), followed by the physically unattainable, post-peak solutions (dashed lines). The approach of nucleation is noticeable in that a modest increase of pore pressure results in a significant growth of the rupture tips and of the amount of slip. Figure $4 \mathrm{~b}$ shows comparable plots for the shear stress. Plotting its ratio with the effective normal stress in Figure 4c shows the weakening of the friction coefficient from its peak value (here arbitrarily chosen to be $\left.f_{p}=0.5\right)$. The overall peaked structure of Figure $4 \mathrm{c}$ is owed to the peaked distribution of the pore pressure increase.

From this analysis, the most unstable form of loading is a broad increase in pore pressure, in the sense that loadings of this type require the lowest peak pore pressure and result in the shortest critical lengths (as well as the least amount of slip at nucleation). Given that $\mu^{*}$ is larger in mode II than in mode III, rupture growth in mode III will reach its critical value sooner than in mode II, provided pore pressure increases have approximately equal distribution in the alongslope and across-slope directions. Additionally, for sharper pore pressure increases, the trend of their unstable points is towards the point where frictional strength of the interface is lost $(T=1)$. While our model is limited to $T<1$, we will later briefly discuss potential modes of failure once $T=1$.

\subsection{Residual friction and dynamic rupture arrest implications}

A residual friction coefficient $f_{r}$, typically a moderate fraction of $f_{p}$, is engaged at a slip of $\delta_{c}$ and such a cutoff affects rupture propagation. If the initial shear stress is sufficiently low such that $\tau_{o}<f_{r} \sigma_{o}^{\prime}\left(\equiv \tau_{r}\right)$ and rupture is initiated with relatively little slip with respect to $\delta_{c}$ (e.g., for low $K$ ) one may expect the rupture to reach instability and proceed dynamically. However, one would also expect the rupture to arrest as sufficient slip accumulates such that the strength approaches its residual value. Garagash and Germanovich [private communication, 2010] observed such a potential for dynamic rupture arrest for their in-plane point-source loading scenario. Furthermore, dynamic rupture may potentially be reinitiated with further increase in pore pressure when $\tau_{r}<\tau_{o}<\tau_{p}\left(\equiv f_{p} \sigma_{o}^{\prime}\right)$.

Figure 5a continues solutions of Figure 3 now considering the possibility that slip may exceed the slip weakening distance $\delta_{c}$, engaging residual friction. The solutions shown are those for slopes with very little initial shear stress, as may be the case for very shallow slope angles (low $\tau_{o} / \tau_{p}$ ). Under these low slope angles, the gravitational shear stress would be insufficient to drive a rupture at a nominal residual strength $\tau_{r}=f_{r} \sigma_{o}^{\prime}$. Not surprisingly then we find that the dynamic rupture arrests once it has progressed away from the peak in pore pressure into a region that is closer to the ambient effective normal stress $\sigma_{o}^{\prime}$. The dynamic rupture initiation and arrest are marked for the particular case $f_{r} / f_{p}=0.5$ by the points (A) and (B), respectively. The arrest lengths are longer for lower residual strengths, $f_{r} / f_{p}$. Continued quasistatic slip and growth of the rupture is possible after arrest. However, this requires continued pore pressure increases that eventually would require reaching the slope-normal stress. (Also shown are unphysical solutions when a residual friction is neglected and friction is allowed to follow the linear slip-weakening path into the negative range.)

Not all ruptures will arrest and Figure 5b shows the effect of increasing the slope angle. Continuing with the solution for $f_{r} / f_{p}=0.5$ in red of Figure $5 \mathrm{a}$, we increase the background shear stress $\tau_{o}$, which is measured using a prestress 

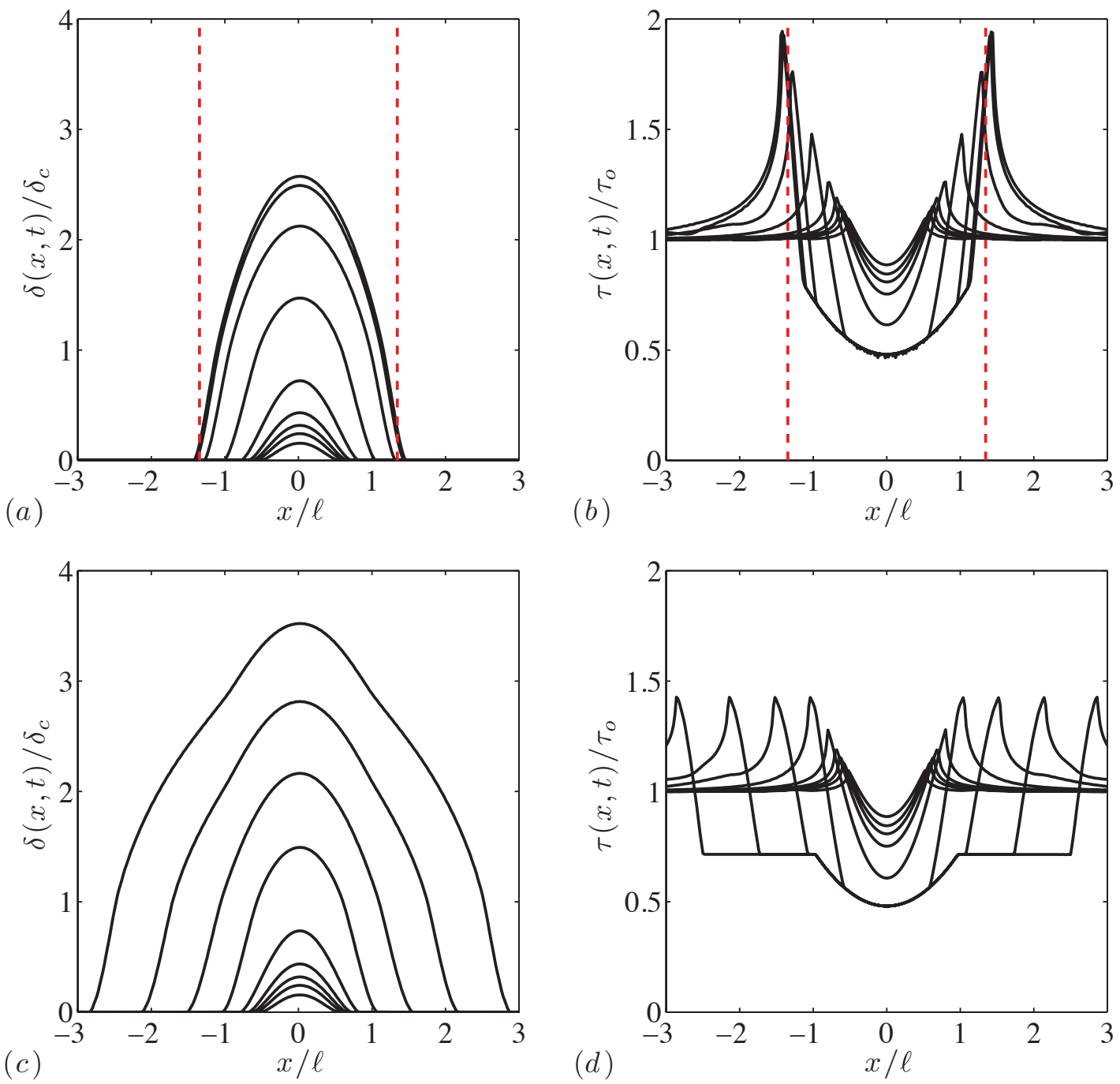

Figure 6. Dynamic rupture arrest (Case 1, a-b) and continuation (Case 2, c-d) as indicated by plots of slip and shear stress at time intervals of $\ell / c_{s}$. The cases correspond to two cases of Figure $5 \mathrm{~b}$. In both cases $f_{r} / f_{p}=0.5$, and the sole difference is an increase in shear stress from $\tau_{o} / \tau_{p}=0.5$ for Case 1 to $\tau_{o} / \tau_{p}=0.7$ for Case 2. Each rupture is nucleated by suddenly applying the same critical loading $\Delta p\left(x, t_{c}\right)$ (with profile curvature $K=1$ ) as the initial condition. The dashed lines in (a-b) correspond to arrest length predicted by quasi-static solution (point (B) in Figure 5b).

ratio

$$
r \equiv \frac{\tau_{o}-\tau_{r}}{\tau_{p}-\tau_{r}} \equiv \frac{1}{1+S}
$$

(as an alternative to the commonly used $S$-ratio in fault rupture dynamics). Here we find that by increasing $\tau_{o} / \tau_{p}$ (more specifically, $r$ ), there is a transition of ruptures that arrest (e.g., the cases $r=-1, r=0$ ) to those that may continue to propagate dynamically once initiated $(r=0.4)$.

There is an intermediate case shown in which rupture arrests (B'), and, if pore pressures continue to increase, a second nucleation event may occur $(\mathrm{C})$ at which point the rupture propagates indefinitely. The instabilities of the (C)type occur for low, positive $r$. At the point (C) the friction has reached residual over much of the length of the crack. Viesca-Falguières and Rice [2010] made use of a small-scale yielding approximation (i.e., singular crack theory with critical energy release rate $\left.\left(f_{p}-f_{r}\right) \sigma_{o}^{\prime} \delta_{c}\right)$ to examine this behavior and found the crack length at the (C)-type instability, $a_{c}^{(C)} / \ell^{*}$, scaled as $1 /\left(4 \pi r^{2}\right)$ in the small- $r$ limit.

Arrest may be precluded if the friction at large slip is further reduced by additional mechanisms. For deep-seated landslides undergoing rapid slip, shear heating may be suf- ficient to elevate temperatures for thermal pressurization or material decomposition to occur [Voight and Faust, 1982; Vardoulakis, 2002; Goren et al., 2010]. In the fault nucleation context, Garagash and Germanovich [2011] estimated the expected pressurization during the dynamic phase to effectively reduce the domain over which arrest is expected. In the context of rate-and-state friction, this breakthrough effect of such dynamic weakening is imaginable to extend to regions that are nominally rate-strengthening at low slipvelocities [e.g., Noda and Lapusta, 2011; Faulkner et al., 2011].

\subsection{Elastodynamic solutions with rupture arrest}

This predicted dynamic growth and arrest may be observed in finite-element simulations of dynamic rupture propagation in response to a sudden application of the critical pore pressure increase $\Delta p\left(x, t_{c}\right)$. Specifically, in place of modeling the quasi-static process of nucleation to the critical crack size followed by the dynamic growth process, an elastodynamic problem is considered with $\Delta p\left(x, t_{c}\right)$ as the initial condition, which is discretized over the contact surface as a position-dependent, nodal pore-pressure force. This 
pore-pressure force reduces the effective normal force when evaluating the frictional strength of a node. We use the finite element package ABAQUS/Explicit in a similar manner as that by Templeton and Rice [2008] and Viesca et al. [2008], except to be consistent with our quasi-static model, only considering elastic behavior away from the contact surface. (Those investigations, as well as those of Viesca and Rice [2010], considered elastic-plastic response of material outside the slip surface.)

The finite-element grid spacing is $\Delta x=\ell / 50$ and the domain (discretized with four-noded plane-strain, reduced integration elements) has a height and width of $10 \ell \times 20 \ell$, with a split-node contact surface located at half-height and absorbing boundary conditions ("infinite" elements) along the outer boundaries. Two cases are considered for which $K=1$ and $f_{r} / f_{p}=0.5$ : Case 1) $\tau_{o} / \tau_{p}=0.5$, and Case 2) $\tau_{o} / \tau_{p}=0.7$. Plots of slip at constant intervals of time, $\Delta t=\ell / c_{s}$ (where $c_{s}$ is the shear wave speed), show the gradual growth beyond the critical crack length and the subsequent propagation. Case 1) (Figure 6a and b) arrests at a distance close to that estimated by the quasi-static calculation and denoted by the dashed lines. Case 2) (Figure $6 \mathrm{c}$ and d), for which the sole change is an increase in background shear stress, shows indefinite rupture propagation. Such behavior is not restricted to nucleation by pore pressure, but can also be shown to occur in nucleation by local increases in shear stress as in Ampuero et al. [2006] and Ripperger et al. [2007]. Their studies show, that for a slipweakening rupture nucleated by a local peak in the shear stress, net increases in a heterogeneous background shear stress (i.e., an increase in a measure comparable to $r$ ) mark a sharp transition from arresting dynamic ruptures to those that rupture the entire fault surface.

\subsection{Nucleation near a free surface}

To account for a rupture comparable in length to its depth below the free surface, the change in shear stress due to slip requires additional terms to the integral of (16)

$$
\tau(x, t)=\tau_{o}-\frac{\mu^{*}}{2 \pi} \int_{a_{-}(t)}^{a_{+}(t)} \frac{\partial \delta(\xi, t)}{\partial \xi}\left[\frac{1}{x-\xi}+k_{1}(x-\xi)\right] d \xi
$$

and the strength requirement in this case is

$$
\tau(x, t)=\left[f_{p}-w \delta(x, t)\right]\left[\sigma_{o}^{\prime}+\Delta \sigma(x, t)-\Delta p(x, t)\right]
$$

where changes in the total normal stress on the surface due to slip are

$$
\Delta \sigma(x, t)=-\frac{\mu^{*}}{2 \pi} \int_{a_{-}(t)}^{a_{+}(t)} \frac{\partial \delta(\xi, t)}{\partial \xi} k_{2}(x-\xi) d \xi
$$

The nonsingular kernel functions $k_{1,2}(x-\xi)$ account for shear and total normal stress changes, respectively, due to slip in proximity of a free surface. When the rupture length is much less than the depth, then the contributions of those kernels are negligible and (21) reduces to (16), the standard equation for shear stress (with no normal stress change) due to a distribution of dislocations along a planar surface. Taking $v \equiv x-\xi$, the kernals are [e.g., Head, 1953]

$$
\begin{aligned}
& k_{1}(v) \equiv \frac{-v}{4 h^{2}+v^{2}}+\frac{8 h^{2} v}{\left(4 h^{2}+v^{2}\right)^{2}}+\frac{4 h^{2} v^{3}-48 h^{4} v}{\left(4 h^{2}+v^{2}\right)^{3}} \\
& k_{2}(v) \equiv \frac{24 h^{3} v^{2}-32 h^{5}}{\left(4 h^{2}+v^{2}\right)^{3}}
\end{aligned}
$$

For a symmetric distribution of slip near the free surface, their contribution is an antisymmetric change in normal stress and a symmetric change in the shear stress. (As summarized in Viesca and Rice [2011], misprints in early reported results for such kernels have unfortunately propagated through the literature.)

The depth $h$ should be measured relative to a depthindependent lengthscale. This excludes $\ell$ (and $\ell^{*}$ ), as its definition depends on $\tau_{o}$ (or $\sigma_{o}^{\prime}$ ), which is proportional to depth for the simple infinite slope model: $\tau_{o}=\gamma_{b} h \sin \theta$. One depth-independent lengthscale is the geometric mean
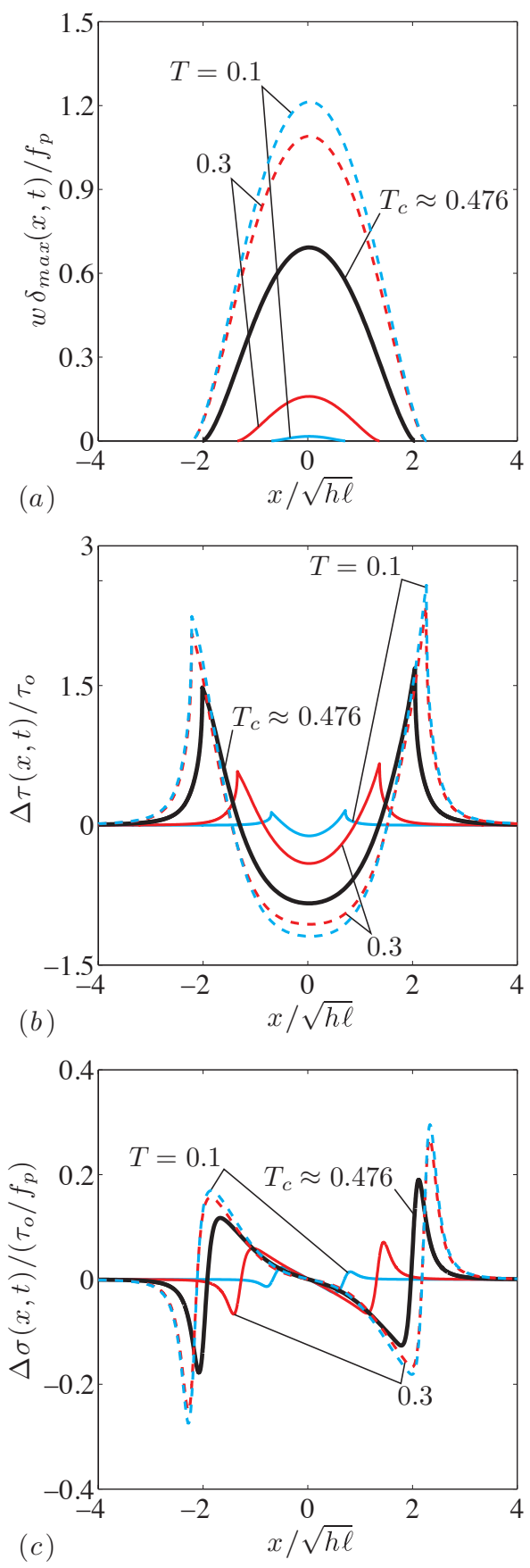

Figure 7. Distribution of (a) slip, (b) shear stress, and (c) total normal stress for given pore pressure increase $T$ with a fixed curvature (normalized such that $\left.K_{h l} \equiv f_{p} \kappa h \ell / \tau_{o}=1\right)$, and fixed effective depth $(H \equiv$ $\sqrt{h / \ell}=0.1$, such that $x$-axis limits are $\pm 40 h)$. Curves in black outline those distributions originating from a nucleated crack of zero length to an unstable limit (bold). 

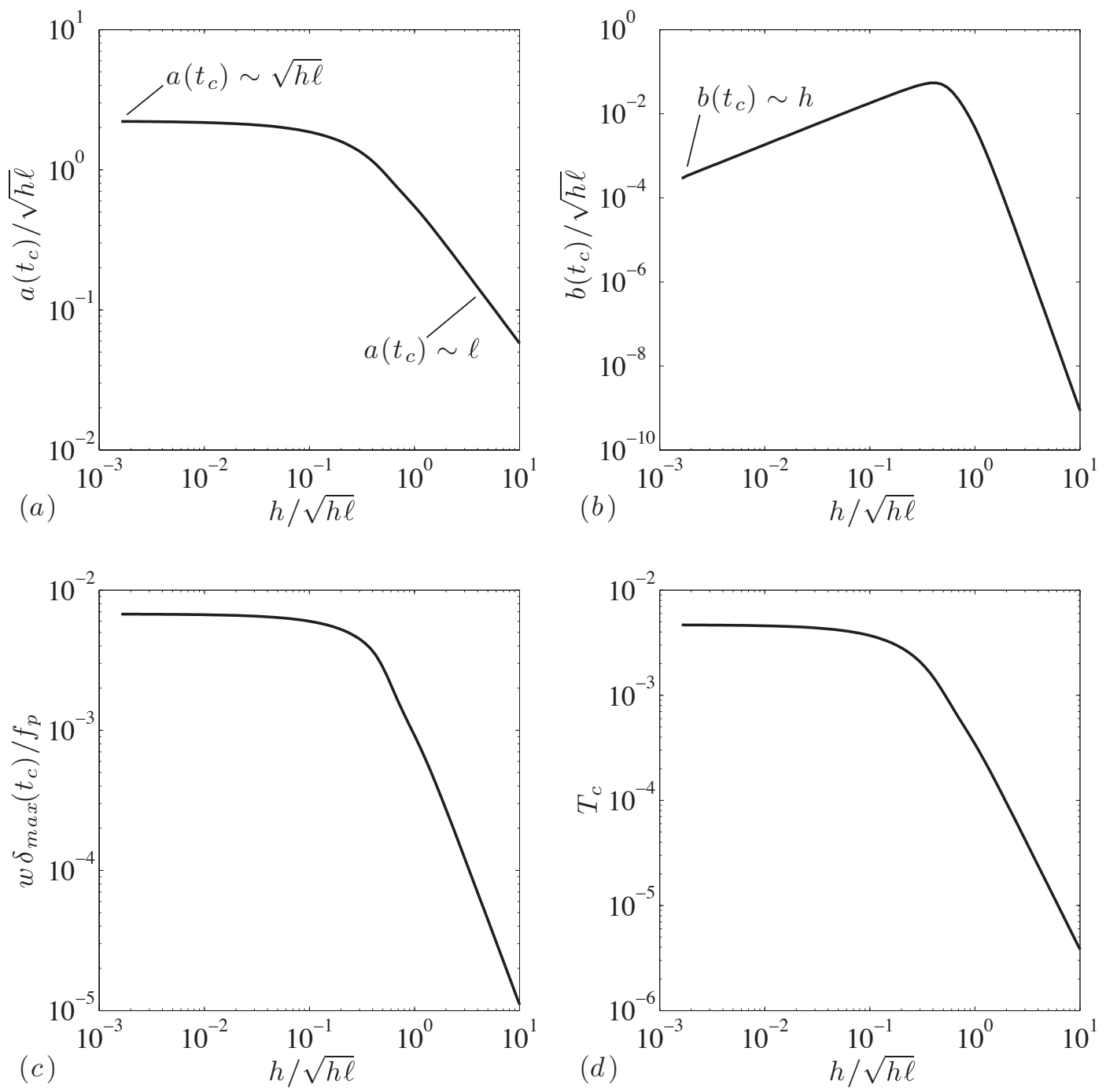

Figure 8. (a) Crack half-length, (b) crack asymmetry, (c) peak slip, and (d) pore pressure increase all at the nucleation condition for $f_{p}=0.5$, fixed non-dimensional pore pressure curvature $\left(K_{h l} \equiv f_{p} \kappa h \ell / \tau_{o}=0.01\right)$, and variable effective depth $(H \equiv \sqrt{h / \ell})$. For such broad increases in pore pressure, the plots show and a limiting behavior for ruptures much longer than their depth, and particularly a transition in nucleation behavior from an effectively deep scaling at large $H, a\left(t_{c}\right) \approx 0.579 \ell$, to a shallow one at low $H, a\left(t_{c}\right) \approx 2.2 \sqrt{h \ell}$. The former scaling follows from the eigenvalue problem of Uenishi and Rice [2003], and the latter from a comparable eigenvalue problem in Appendix A2.

of frictional length $\ell$ and depth $h$

$$
\sqrt{h \ell} \equiv \sqrt{\frac{\mu^{*} f_{p}}{\gamma_{b} \sin \theta w}}
$$

which depends purely on slope orientation and material properties, which are implicitly assumed here to be independent with depth, to first approximation. This lengthscale enters naturally into shallow slope problems and are what scale the critical lengths in shallowly buried fracture analyses of slopes (e.g., $l_{u}$ in Puzrin and Germanovich [2005], which corresponds to $\sqrt{4 h \ell^{*}}$ here). The nondimensional depth is then defined as

$$
H \equiv \frac{h}{\sqrt{h \ell}}
$$

Estimates of $H$ in subaerial and submarine environments yields a perhaps surprisngly narrow range, assuming similar weakening behavior in both environments when estimating $\ell$. Taking the representative scenarios used to estimate $\ell^{*}$ in the introduction of Section 4 , yields $\ell=4.4-44 \mathrm{~m}$ and $H=0.34-1.1$ in the subaerial case and for the submarine case (hydrostatic conditions), $\ell=43-430 \mathrm{~m}$ and $H=0.22-$ 0.68 .

We look for the nucleation behavior at variable depth, with an interest in the limit of small and moderate $H$. We use a locally peaked pore pressure profile as in (12) with a spatially uniform loading at rate $T$, but here choose a nondimensionalization of the curvature using the depthindependent lengthscale $\sqrt{h \ell}$

$$
K_{h \ell} \equiv \frac{f_{p}}{\tau_{o}} \kappa h \ell
$$

Then, fixing $K_{h \ell}$, the only parameter varied is the burial depth of the sliding surface. Additionally, for the cases considered here the friction coefficient is presumed to remain on the linear portion of the slip-weakening curve (i.e., the slip remains below $\delta_{c}$ ).

Figure 2 shows the geometry of the crack and the pore pressure profile at nucleation for the particular case $H=0.5$, 
$K_{h \ell}=1, \tau_{o} / \sigma_{o}^{\prime}=0.25$ and $f_{p}=0.5$. Considering a scenario that leads to quasi-static crack lengths much longer than depth, Figure 7 shows slip distributions, shear stress and normal stress changes at various levels of loading $T$ up to (solid) and beyond (dashed) the point of nucleation.

In Figure 8 we plot the average crack lengths $a\left(t_{c}\right)$, asymmetry length $b\left(t_{c}\right)$, peak slip $\delta_{\max }\left(t_{c}\right)$, and pore pressure increase $T_{c}$ at the point of nucleation of dynamic rupture as they depend on the depth $H$, considering the particular case $K_{h l}=0.01$. Plotting nucleating crack lengths (Figure 8a), there is a clear transition from an effectively deep regime where $a\left(t_{c}\right) \sim \ell$ to a shallow regime in the limit $H \rightarrow 0$ where $a\left(t_{c}\right) \sim \sqrt{h \ell}$. Similarly to the deep limit for such broad increases, the nucleating pore pressure increases (beyond that required to start sliding) and peak slip are also small and tend towards fixed values in the shallow limit (Figure 8c,d). Interestingly, the rupture asymmetry measure at nucleation, $b\left(t_{c}\right)$, increases as rupture lengths become progressively shallower, with a peak when $\ell$ and $h$ become comparable (Figure 8b). At shallower conditions, the asymmetry decreases and scales as $b\left(t_{c}\right) \sim h$ and at all depths the value $b\left(t_{c}\right)$ is much smaller than the length $a\left(t_{c}\right)$. Given that it is the normal stress change, $\Delta \sigma$, that contributes to rupture asymmetry, this implies that its contribution is comparatively small. Consequently, we neglect this term to arrive at the eigenvalue problem of Appendix A2. In solving that eigenvalue problem in the limit $K_{h l} \rightarrow 0$ for a range of $a\left(t_{c}\right) / h$, we closely reproduce the solution of Figure $8 \mathrm{a}$. In the shallow limit, the eigenvalue corresponds to the critical crack length $a\left(t_{c}\right) \approx 2.2 \sqrt{h \ell}$. As for nucleation far from the free surface, the nucleation lengths in proximity to the surface are also relatively insensitive to the sharpness of the pore pressure profile. Increasing the sharpness by two orders of magnitude to $K_{h \ell}=1$ leads to a nucleation length in the shallow limit of $a\left(t_{c}\right) \approx 2.5 \sqrt{h \ell}$. (While the rupture length varies little, the peak slip and pore pressure increase at nucleation in this sharper case do increase: $\bar{\delta}_{\max }\left(t_{c}\right) \approx 0.85$ and $T_{c} \approx 0.65$.)

As discussed in the introduction, much of the early work applying fracture mechanics to slope stability essentially assumed that conditions were such that the critical length was in this "shallow" regime. According to the results here, this seems to be a reasonable assumption provided the depth measure $H$ is sufficiently low. Since $H$ is the square root of ratio of $h / \ell$ (or alternatively, $h / \ell^{*}$ ), it may be difficult to meet a condition that $H<10^{-2}$, where results generally appear to become depth-independent and critical crack lengths scale as $\sqrt{h \ell}$ (or $\sqrt{h \ell^{*}}$ ). For example, to meet the criterion $H=10^{-2}$ with $h=20 \mathrm{~m}$ would require $\ell=200$ $\mathrm{km}$.

\section{Discussion and Conclusions}

We modeled the growth of a landslide slip surface as a shear fracture occurring in an elastic medium. The growth is initially driven by a local high in the pore pressure distribution. Because the strength of the slip surface weakens with slip, a point is reached where the slip surface may continue to grow without any further increase in pore pressure. This growth is fast and dynamic and is taken to be the onset of gravitational acceleration of the landslide downslope.

This dynamic growth of the slip surface may arrest, and with it, the downslope acceleration of the landslide mass. Shallow slopes, like those typically found on the seafloor, are particularly susceptible to arrest. Continued acceleration of the slope is dependent either on further increases in pore pressure or dramatic weakening mechanisms during the period of rapid slip.

The relevant lengths are the depth of the slip surface, $h$, and a lengthscale $\ell$ that arises from the slip-weakening behavior of the surface. We calculate the length of the slip surface and the slip accrued at the onset of catastrophic failure, as well as the pore pressure required to reach this onset. When pore pressure increases are very broad we find that the total length of the rupture at onset, $2 a\left(t_{c}\right)$, depends on a ratio of these two lengths, $H=\sqrt{h / \ell}$.

We plot in Figure 9 the expected nucleation lengths as they depend on depth of the slip surface for submarine and subaerial slope conditions. The predicted nucleation lengths for submarine conditions are nearly an order larger than subaerial. Furthermore, the few-hundred-meter lengths are comparable in size to seafloor pockmarks. As pore pressures that generate pockmarks approach lithostatic conditions, there is the potential to nucleate an event with an initial size of Figure 9. In contrast, the nucleation lengths in subaerial events are predicted to be much smaller. One limitation not considered is the effect of topography, which may limit rupture propagation across- or along-slope. In our analyses we assumed a subsurface rupture running parallel to a uniform slope.

Additionally, we have not investigated the potential continuation of solutions involving other modes of deformation, in addition to the propagation of slip, once pore pressures reach the normal stress. If the least compressive stress is instead inclined towards the slope-parallel direction (e.g., as may occur in normally consolidated slopes), then a hydraulic fracture may be initiated towards the slope surface before pore pressures reach the slope-normal stress. While this fracture would relieve pore pressure on the slip surface, the resulting stress concentrations created by the opening of the fracture may drive slip and propagate the shear rupture. If the least compressive stress is normal to the slope (e.g., in overconsolidated slopes) or if natural layering creates a preferential slope-parallel conduit for fluid flux, then a hydraulic fracture may be initiated. This fracture would be an efficient means of redistributing pore pressures at the level of the normal stress, effectively creating a region with no shear resistance. With continued fluid supply enlarging the weakened zone, the shear rupture may continue towards instability.

\section{Appendix A: Nucleation lengths for broad- curvature pore pressure profiles and the corresponding eigenvalue problems}

\section{A1. Nucleation lengths much smaller than depth}

Following a similar procedure outlined in greater detail in Uenishi and Rice [2003], we combine (12) with (16-17), using $q(x)=\kappa x^{2} / 2$,

$$
\begin{array}{r}
{\left[f_{p}-w \delta(x, t)\right]\left[\frac{\tau_{o}}{f_{p}}-R t+\frac{1}{2} \kappa x^{2}\right]=} \\
\tau_{o}-\frac{\mu^{*}}{2 \pi} \int_{a_{-}(t)}^{a_{+}(t)} \frac{\partial \delta(\xi, t) / \partial \xi}{x-\xi} d \xi
\end{array}
$$

We take a derivative with respect to time, noting that in the derivative of the integral the terms evaluated at the boundary vanish by the requirement of non-singular stresses at the crack tip

$$
\begin{array}{r}
-w V(x, t)\left[\frac{\tau_{o}}{f_{p}}-R t+\right. \\
\left.\frac{1}{2} \kappa x^{2}\right]-R\left[f_{p}-w \delta(x, t)\right]= \\
-\frac{\mu^{*}}{2 \pi} \int_{a_{-}(t)}^{a_{+}(t)} \frac{\partial V(\xi, t) / \partial \xi}{x-\xi} d \xi
\end{array}
$$

where $V(x, t)$ is the slip velocity. We use $a(t)=\left(a_{+}-a_{-}\right) / 2$, $b(t)=\left(a_{+}+a_{-}\right) / 2, X=[x-b(t)] / a(t)$, and scale slip velocity by its rms value, $\mathcal{V}=V(x, t) /\left[\sqrt{2} V_{r m s}(t)\right]$ to arrive 

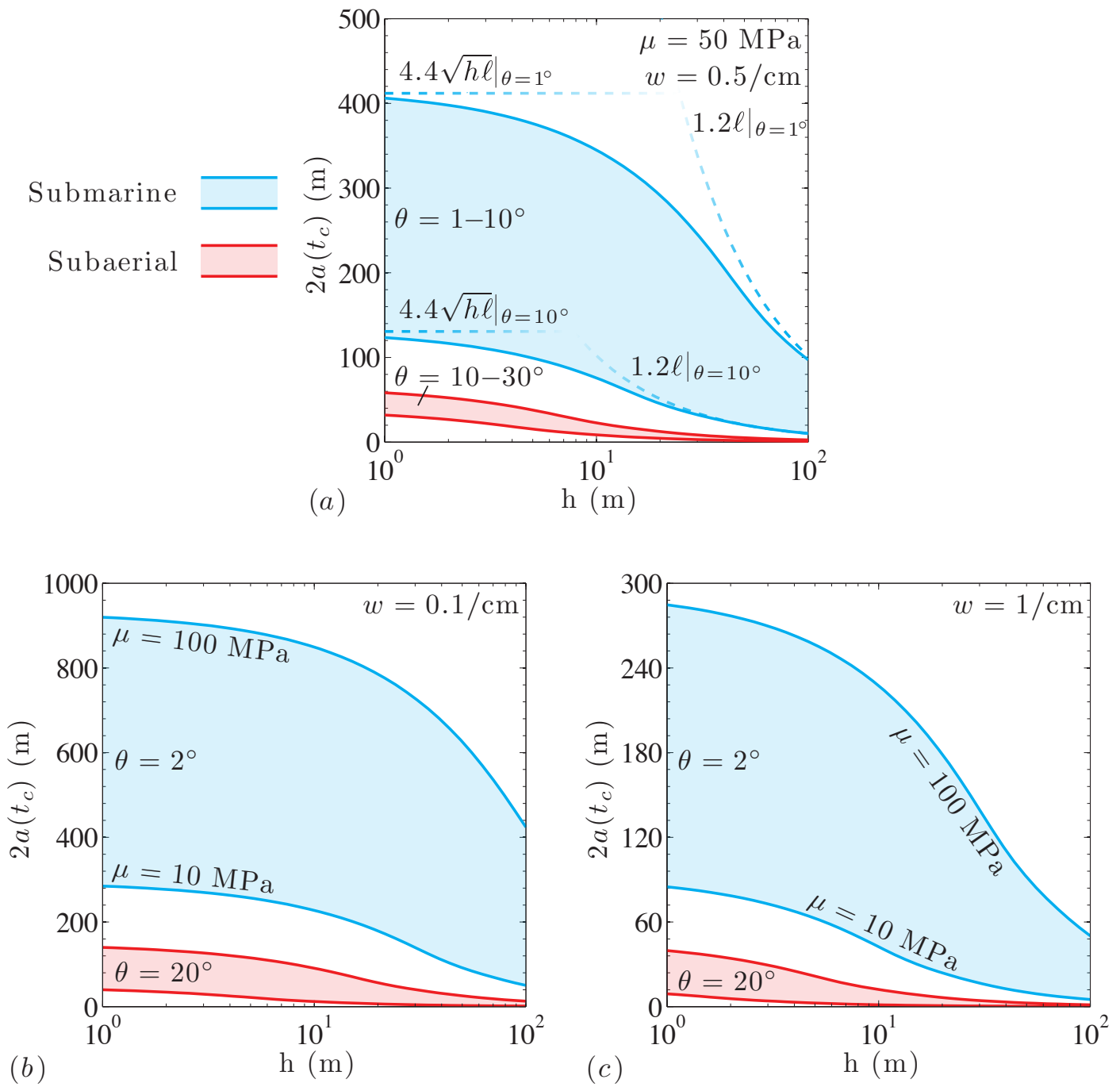

Figure 9. Variation of critical slip surface lengths, $2 a\left(t_{c}\right)$, with burial depth under submarine and subaerial conditions. These lengths mark the onset of dynamic slip surface growth and downslope acceleration. Solutions presented for case where pore pressures are nearly uniformly elevated over the length $2 a\left(t_{c}\right)$ (as in Figure 8a). Submarine conditions reflect a sediment bulk weight of $\gamma_{b}=1.5 \gamma_{w}$ and shallow slope angles. Subaerial conditions reflect $\gamma_{b}=2 \gamma_{w}$ and steeper slopes. In all cases the Poisson ratio is $\nu=1 / 3$ and peak friction is $f_{p}=0.5$. Results in (a) are for a range of slope angles in both environments; intermediate values of the slip-weakening rate $w$ and shear modulus $\mu$ are used. The dashed lines show the scalings of nucleation lengths in the "deep" and "shallow" limits for the bounding submarine cases. Results in (b) and (c) are, respectively, for low and high slip-weakening rates $w$, each over a range of sediment stiffnesses.

at

$$
\begin{gathered}
-\frac{w}{\mu^{*}} a(t) \mathcal{V}(x, t)\left[\frac{\tau_{o}}{f_{p}}-R t+\frac{1}{2} \kappa x^{2}\right]- \\
\frac{R a(t)}{\mu^{*} \sqrt{2} V_{r m s}}\left[f_{p}-w \delta(x, t)\right]=-\frac{1}{2 \pi} \int_{-1}^{+1} \frac{\partial \mathcal{V}(s, t) / \partial s}{X-s} d s
\end{gathered}
$$

For the quasi-static problem, $V_{r m s}(t)$ diverges at the onset of the nucleation of dynamic rupture. Consequently, we can neglect the second term in the above. After dropping explicit mention of the time-dependence of variables and nondimensionalizing, we find at nucleation that the slip velocity satisfies

$$
\left[1-T+K \frac{(\bar{a} X+\bar{b})^{2}}{2}\right] \bar{a} v(X)=\frac{1}{2 \pi} \int_{-1}^{+1} \frac{v^{\prime}(s)}{X-s} d s
$$

The term in brackets is the normalized effective normal stress $\sigma^{\prime}(x, t) f_{p} / \tau_{o}$. In the limit that the normalized curvature is very broad $(K \rightarrow 0)$, the problem reduces to the eigenvalue problem of Uenishi and Rice [2003] for which the critical length $\bar{a}\left(t_{c}\right)$ approaches its shortest length at the smallest eigenvalue $\lambda_{o} \approx 0.579$, when the pore pressure increase is minimally beyond that required to initiate sliding (i.e., $T \rightarrow 0$ ). Similarly, Garagash and Germanovich [2011] reduce their fault injection problem to such an eigenvalue problem to conveniently calculate critical conditions for variable pressurization scenarios.

\section{A2. Nucleation lengths approaching and exceeding depth}

Following the same steps that lead to (9), except here accounting for the free surface (i.e., now using (22), but neglecting $\Delta \sigma$ as a negligible contribution) we arrive at a 


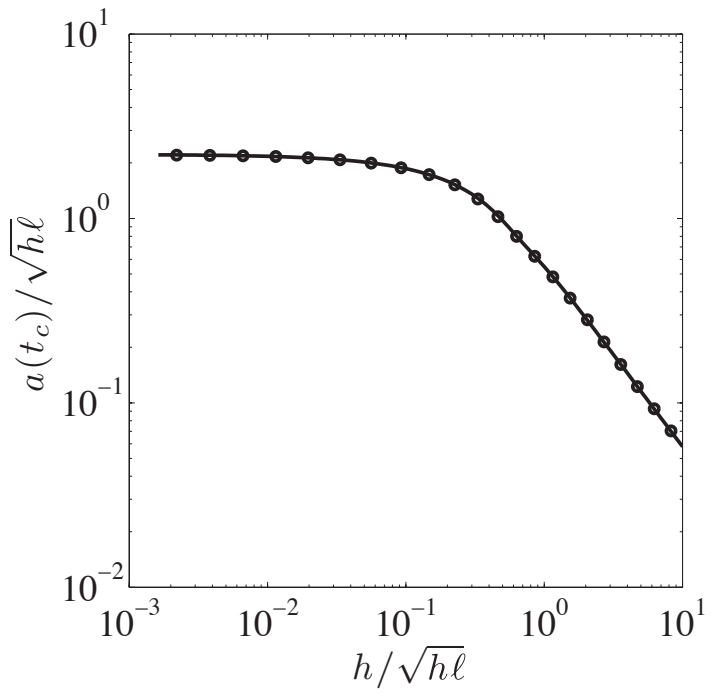

Figure A1. Comparison of numerical solutions for crack length at nucleation, $a\left(t_{c}\right) / \sqrt{h \ell}$ with dimensionless depth $h / \sqrt{h \ell}$ of Figure $8 \mathrm{a}$ (solid line) against solutions to the eigenvalue problem of (A5) in the limit of very broad pore pressure increases, $K_{h l} \rightarrow 0$ (circles).

similar eigenvalue problem

$$
\begin{aligned}
& {\left[1-T+\frac{K_{h \ell}}{2}\left(\frac{a X+b}{h l}\right)^{2}\right] \frac{a}{\ell} v(X)} \\
& =\frac{1}{2 \pi} \int_{-1}^{1} v^{\prime}(s)\left\{\frac{1}{X-s}+k_{1}[a(X-s)] a\right\} d s
\end{aligned}
$$

When $K_{h l} \rightarrow 0$, the problem reduces to the same eigenvalue problem as would result for the shear-stress loading scenario considered by Uenishi and Rice [2003] had the fault in that scenario lain parallel to the free surface and been driven to slip over a region much longer than its depth. Returning to the pore pressure scenario here and to the limit $K_{h \ell} \rightarrow 0$ of (A5), the lowest eigenvalue corresponds to the nucleation length $a\left(t_{c}\right) / \ell$ for a given $h / a\left(t_{c}\right)$. In the broad curvature limit, solution of the eigenvalue problem for variable $h / a\left(t_{c}\right)$ reproduces remarkably closely the full numerical solution (Figure A1), such that the critical length may be expressed as

$$
\frac{a\left(t_{c}\right)}{\sqrt{h \ell}} \approx \lambda_{h, o}(H)
$$

where $\lambda_{h, o}$ is the lowest eigenvalue of (A5) (after dividing by $H \equiv \sqrt{h / \ell})$. To highlight the limit of small $h / a\left(t_{c}\right)$, the smallest eigenvalue in that limit is

$$
\frac{a\left(t_{c}\right)}{\sqrt{h \ell}} \approx \lambda_{h, o}(H \rightarrow 0) \approx 2.2
$$

In the case of shear-stress loading, this nucleation length is $a\left(t_{c}\right) / \sqrt{\mu^{*} h / W} \approx \lambda_{h, o}(H)$. The key result of the deepfault case of Uenishi and Rice [2003] is maintained: namely that this nucleation length is independent of the shape the elevated shear stress profile takes.

\section{Appendix B: Solution by collocation method using Gauss-Chebyshev quadrature}

Here we outline the numerical method used to solve for crack lengths and slip distributions for given increases in pore fluid pressure. We rely on methods commonly used in fracture problems where the evaluation of the integrals appearing in (16), (21), and (23) is approximated by GaussChebyshev quadrature [e.g., Erdogan and Gupta, 1972; Erdogan et al., 1973]. We find that these direct numerical solutions are favorable to a variational approximation [e.g., Rice and Uenishi, 2010], which, while a fairly accurate approximation for broadly peaked profiles, break down as the curvature increases (see Appendix C). Furthermore, this means of numerical solution is preferred other over common methods, such as approximating the slip distribution by piecewise-continuous domains of constant slip [e.g., Rice and Uenishi, 2010] or more involved quadratures such as that of Gerasoulis and Srivastav [1981]. The advantage over the former method is owed to the higher accuracy accompanying a higher order of convergence (second order versus first), and the preference over the latter, in which both accuracy and order are comparable, is owed to the relative ease of implementation.

Gauss-Chebyshev quadrature approximates an integral

$$
\int_{-1}^{1} \frac{F(\xi)}{\sqrt{1-\xi^{2}}} d \xi \approx \frac{\pi}{n} \sum_{j=1}^{n} F\left(\xi_{j}\right)
$$

where $\xi_{j} \equiv \cos [\pi(2 j-1) /(2 n)]$. When $F(\xi)$ takes the form of the singular kernel $1 /(x-\xi)$, or some bounded kernal $k(x-\xi)$, the quadrature approximation holds at collocation points $x=x_{i} \equiv \cos (\pi i / n)$ where $i=1,2, \ldots, n-1$.

\section{B1. Ruptures with no residual friction}

We use the above quadrature rule to simplify the integral in (16). With a change of variable $X=(x-b) / a$, where $a=\left(a_{+}-a_{-}\right) / 2$ and $\left.b=\left(a_{+}-a_{-}\right) / 2\right)$

$$
\int_{a_{-}}^{a_{+}} \frac{d \delta(\xi) / d \xi}{x-\xi} d \xi=\frac{1}{a} \int_{-1}^{1} \frac{d \delta(s) / d s}{X-s} d s
$$

We may reduce the latter integral to the form of (B1) defining a function $\phi(s)$

$$
\frac{d \delta(s)}{d s} \equiv \frac{\phi(s)}{\sqrt{\left(1-s^{2}\right)}}
$$

such that

$$
\int_{-1}^{1} \frac{1}{\sqrt{1-s^{2}}} \frac{\phi(s)}{X_{i}-s} d s \approx \frac{\pi}{n} \sum_{j=1}^{n} \frac{\phi\left(s_{j}\right)}{X_{i}-s_{j}}
$$

where $X_{i}$ and $s_{j}$ are defined respectively as $x_{i}$ and $\xi_{j}$ are defined above.

Implicit in this quadrature is the approximation

$$
\phi(s) \approx \sum_{m=0}^{p} B_{m} T_{m}(s)
$$

where $p<n$ and $T_{j}(s)$ is the $j$-th Chebyshev polynomial of the first kind. With $\phi\left(s_{j}\right)$ abbreviated $\phi_{j}$, this may be rewritten (with summation implied by repeated indices in what follows)

$$
\phi_{j}=C_{j m} B_{m}
$$

where $C_{j m}=T_{m}\left(s_{j}\right)$. Using (B3) and (B5), an approximate expression for the slip at $X_{i}\left(\right.$ abbreviated $\left.\delta_{i}\right)$ is

$$
\begin{aligned}
\delta_{i} & \approx \int_{-1}^{X_{i}} \frac{B_{m} T_{m}(s)}{\sqrt{1-s^{2}}} d s \\
& =\left[\arcsin \left(X_{i}\right)+\frac{\pi}{2}\right] B_{o}+\frac{\sin \left[k \arccos \left(X_{i}\right)\right]}{k} B_{k} \\
& =D_{i m} B_{m}
\end{aligned}
$$


$(k=1,2, \ldots, p)$. Using (B5) and (B7),

$$
\delta_{i}=S_{i j} \phi_{j}
$$

where $S_{i j}=D_{i m} C_{j m}^{-1}$.

(Alternatively, we may have taken the simpler approximation

$$
\delta_{i}=\int_{-1}^{1} \frac{\phi(s)}{\sqrt{1-s^{2}}} H\left(X_{i}-s\right) d s \approx \tilde{S}_{i j} \phi_{j}
$$

where $H(x)$ is the Heaviside step function and $\tilde{S}_{i j}$ is a strictly upper triangular matrix of entries $\pi / n$. The advantage of $S_{i j}$ over $\tilde{S}_{i j}$ is that, for cases where $\phi(s)$ may be expressed as a finite sum of Chebyshev polynomials and $\phi_{j}$ is provided exactly, $S_{i j}$ will provide exact values of slip $\delta_{i}$. However, in practical application the two yield close results since $S_{i j}$ and $\tilde{S}_{i j}$ differ only slightly.)

As a result of the preceding, we may combine (16-17) to arrive at the following integral equation (for ruptures far from the free surface)

$$
\left[f_{p}-w \delta(x)\right]\left[\sigma_{o}^{\prime}-\Delta p(x)\right]=\tau_{o}-\frac{\mu^{*}}{2 \pi} \int_{a_{-}}^{a_{+}} \frac{d \delta(\xi) / d \xi}{x-\xi} d \xi
$$

which then may be considered at discrete points $x_{i} \equiv a X_{i}+b$ and reduced to the form

$$
\left[f_{p}-w S_{i j} \phi_{j}\right]\left[\sigma_{o}^{\prime}-\Delta p\left(a X_{i}+b\right)\right]=\tau_{o}-K_{i j} \phi_{j}
$$

where $K_{i j}=\mu^{*} /\left[2 n a\left(X_{i}-s_{j}\right)\right]$. For a given pore pressure increase $\Delta p(x)$, the index $i$ provides a set of $n-1$ equations for $n+2$ unknowns $\phi_{j}, a$, and $b$. One additional condition is that there is no net dislocation beyond the crack:

$$
0=\int_{-1}^{1} \frac{\phi(s)}{\sqrt{1-s^{2}}} d s \approx \frac{\pi}{n} \sum_{j=1}^{n} \phi_{j}
$$

and the remaining two are the conditions that the stress intensity factor at each crack tip is zero. From (B3) it is evident that the stress intensity factors at the left and right ends are proportional to $\phi( \pm 1)$. As we seek solutions that have nonsingular stresses, we require that $\phi( \pm 1)=0$. Using interpolation to approximately determine $\phi( \pm 1)$ from $\phi_{j}$ [Krenk, 1975], we arrive at the the following constraints on $\phi_{j}$

$$
\begin{aligned}
& 0=\phi(1) \approx \frac{1}{n} \sum_{j=1}^{n} \frac{\sin [\pi(2 n-1)(2 j-1) /(4 n)]}{\sin [\pi(2 j-1) /(4 n)]} \phi_{j} \\
& 0=\phi(-1) \approx \frac{1}{n} \sum_{j=1}^{n} \frac{\sin [\pi(2 n-1)(2 j-1) /(4 n)]}{\sin [\pi(2 j-1) /(4 n)]} \phi_{n-j+1}
\end{aligned}
$$

For symmetric $\Delta p(x)$, it can be anticipated that $b=0$, and only one stress intensity condition need be imposed.

We may define $n+2$ functions $F_{r}$ where, from (B11),

$$
F_{i} \equiv \tau_{o}-K_{i j} \phi_{j}-\left[f_{p}-w S_{i j} \phi_{j}\right]\left[\sigma_{o}^{\prime}-\Delta p\left(a X_{i}+b\right)\right]
$$

and $F_{n}, F_{n+1}$, and $F_{n+2}$ are simply the right hand sides of (B12-B14). The arguments of the functions are taken as $Y_{r}$ where $Y_{j}=\phi_{j}, Y_{n+1}=a$ and $Y_{n+2}=b$ and the Jacobian of $F_{r}$ may be expressed as

$$
J_{r s}=\frac{\partial F_{r}}{\partial Y_{s}}
$$

For example, the entries $J_{r s}$ over $1 \leq r, s \leq n$ are

$$
\frac{\partial F_{i}}{\partial \phi_{j}}=-K_{i j}+w S_{i j}\left[\sigma_{o}^{\prime}-\Delta p\left(a X_{i}+b\right)\right]
$$

We seek solutions to $F_{r}=0$ and do so using the NewtonRaphson method. Starting with an initial guess $Y_{r}^{0}$, we calculate the resulting $F_{r}^{0}$ and $J_{r s}^{0}$ and a corresponding correction $\Delta Y_{r}^{0}$ by solving

$$
-F_{r}^{0}=J_{r s}^{0} \Delta Y_{s}^{0}
$$

and updating $Y_{r}^{1}=Y_{r}^{0}+\Delta Y_{r}^{0}$. This process is repeated until an $N$-th increment for which $\max \left(\left|\Delta Y_{r}^{N}\right|\right)$ is below a chosen tolerance.

To account for slip occurring near the free surface the additional changes to shear and normal stress are included.
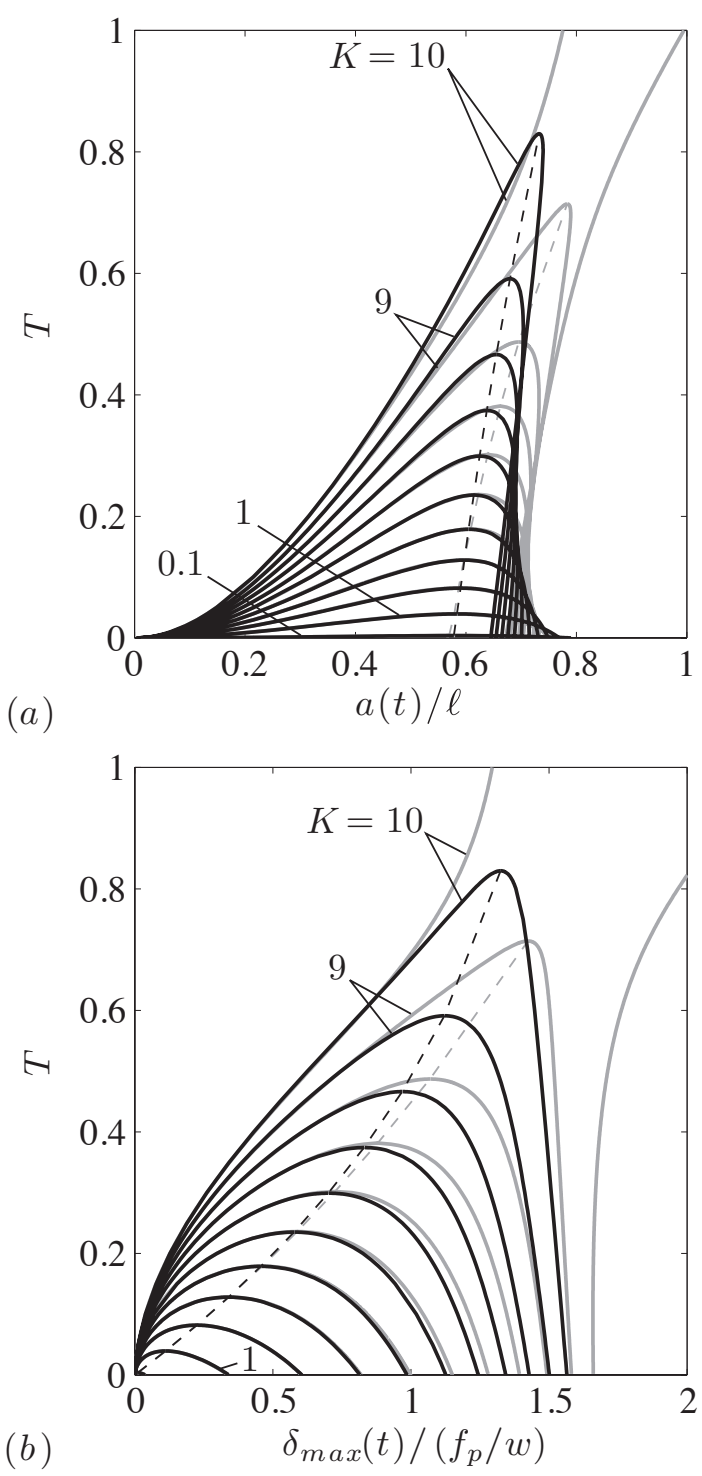

Figure B1. Comparison of solutions for (a) crack length and (b) peak slip arrived at directly by Chebyshev-Gauss quadrature (black), as in Figure 3, and approximately by the simpler variational approach (grey). Dashed lines highlight the divergence, between methods, of the dynamic rupture nucleation point for increasingly peaked pore pressures. 
As a result, (B11) becomes

$$
\begin{array}{r}
{\left[f_{p}-w S_{i j} \phi_{j}\right]\left[\sigma_{o}^{\prime}-\Delta p\left(a X_{i}+b\right)+M_{i j} \phi_{j}\right]} \\
=\tau_{o}-\left(K_{i j}+L_{i j}\right) \phi_{j}
\end{array}
$$

where $L_{i j}=k_{1}\left[a\left(X_{i}-s_{j}\right)\right] \mu^{*} /(2 n)$ and $M_{i j}=k_{2}\left[a\left(X_{i}-\right.\right.$ $\left.\left.s_{j}\right)\right] \mu^{*} /(2 n)$ and in the Newton-Raphson scheme, $F_{i}$ are changed accordingly. While an increment in pore pressure may be symmetric about the origin, due to the symmetrybreaking effect of the free surface, rupture growth will be asymmetric and $b$ nonzero.

\section{B2. Ruptures with residual friction}

For accurate results once residual friction is engaged along the crack, the point in space at which friction transitions from a linearly decreasing function to a residual value must occur at a collocation point $X_{D}$, providing an additional constraint:

$$
S_{D j} \phi_{j}=\delta_{c}
$$

where $\delta_{c} \equiv\left(1-f_{r} / f_{p}\right) f_{p} / w$. To add an corresponding unknown variable, we free a parameter of the pore pressure profile to vary. For the example of the load of type (12): at fixed load curvature $K$ we seek the magnitude of the increase $T$ that corresponds to the slip weakening distance occupying the position (relative to the crack length) $X_{D}$, taking advantage of the monotonic relation apparent from solutions in which the slip weakening position is freely determined. In terms of the Newton-Raphson procedure, we introduce

$$
\begin{aligned}
F_{n+3} & \equiv S_{D j} \phi_{j}-\delta_{c} \\
Y_{n+3} & \equiv T
\end{aligned}
$$

In cases of symmetric rupture growth the position of both slip weakening points will be at the collocation points of $\pm X_{D}$. However, for asymmetric ruptures, this method suffers from the deficiency that only one slip weakening position will be constrained by (B20), however the accuracy is still considerably improved.

\section{Appendix C: Approximate solution by a variational method}

Here we follow an energy approach similar to that outlined by Rice and Uenishi [2010] to estimate the crack length at which its growth rate becomes unbounded when far from the surface. In doing so, we define a functional $M$ of slip $\delta(x)$ (at a given instant in time - $t$-dependence suppressed in below notation) that is $\Delta \tau(x)=-M[\delta(x)]$ where this functional is the integral term in (16), without the additional kernel.

Correspondingly, the functional of change in elastic energy in the body due to slip $\delta$ can be written as an integral over the slipped region

$$
\begin{aligned}
s[\delta(x)]= & \frac{1}{2} \int_{a_{-}}^{a_{+}} M[\delta(x)] \delta(x) d x \\
& -\int_{a_{-}}^{a_{+}} \tau_{o}(x) \delta(x) d x
\end{aligned}
$$

The energy dissipated on the crack surface due to slipweakening friction is

$$
\Phi(\delta)=\int_{0}^{\delta} \tau(\zeta) d \zeta
$$

where the shear strength $\tau(x)$ is given by (17).

For a system with initial energy $U_{o}$, the total energy after slipping is

$$
U=U_{o}+s[\delta(x)]+\int_{a_{-}}^{a_{+}} \Phi[\delta(x)] d x
$$

and for a given pore pressure loading, the system will reach equilibrium when $\Delta U=0$ for arbitrary variations in slip $(\Delta \delta)$ and crack length $(\Delta a)$.

To reach an estimate of the crack length and slip at which growth rate becomes unbounded, we will use an assumed slip distribution that satisfies nonsingular crack tip stresses. In nondimensional form (where $\bar{x}=x / \ell$ and $\bar{\delta}=\delta w / f_{p}$ ), one such slip distribution is $\bar{\delta}(\bar{x})=D\left(A^{2}-\bar{x}^{2}\right)^{3 / 2} / A^{3}$ with length $A$ and slip parameter $D$, both of which will be determined for a given loading profile shape and time.

Evaluating the assumed slip and pore pressure profiles within the energy equation, and defining $\bar{U}=U /\left(\tau_{o} \ell f_{p} / w\right)$, we find

$$
\begin{aligned}
\bar{U}= & \frac{U_{o}}{\tau_{o} L f_{p} / w}+\frac{3 \pi}{32} D^{2}-\frac{3 \pi}{8} D A \\
& +(1-T)\left(\frac{3 \pi}{8} D-\frac{16}{35} D^{2}\right) A \\
& +\frac{1}{2} K\left(\frac{\pi}{16} D-\frac{16}{315} D^{2}\right) A^{3}
\end{aligned}
$$

For a given load increase $T$ and curvature $K$, determining $A$ and $D$ by the simultaneous solution of $\partial U / \partial D=0$ and $\partial U / \partial A=0$ provides an approximate solution of the slip profile. Figure B1 shows the good agreement between the variational approximation and solutions arrived at using the Gauss-Chebyshev quadrature of Appendix B if pore pressure is only shallowly peaked.

Acknowledgments. This study was supported by a research collaboration agreement between Harvard University and Total E \& P Recherche Developpement, an IODP Schlanger Fellowship to R. C. Viesca, and by the Southern California Earthquake Center (SCEC) funded by NSF Cooperative Agreement EAR-0529922 and USGS Cooperative Agreement 07HQAG0008; the SCEC contribution number for this paper is 1527 . The authors are grateful to Dmitry Garagash and Sebastien Garziglia for discussion and thank Dan Faulkner, Steve Miller, and an anonymous reviewer for helpful comments.

\section{References}

Ampuero, J.-P., J. Ripperger, P. M. Mai (2007), Properties of dynamic earthquake ruptures with hetergeneous stress drop, in Radiated Energy and the Physics of Earthquakes, edited by A. McGarr, R. E. Abercrombie, H. Kanamori, and G. Di Toro, pp. 255-261, Geophysical Monograph Series 170, American Geophysical Union, Washington D. C.

Ampuero, J.-P., and A. M. Rubin (2008), Earthquake nucleation on rate and state faults Aging and slip laws, J. Geophys. Res., 113, B01302, doi:10.1029/2007JB005082.

Andrews, B. D., L. L. Brothers, and W. A. Barnhardt (2010), Automated feature extraction and spatial organization of seafloor pockmarks, Belfast Bay, Maine, USA, Geomorphology, 124. 55-64, doi:10.1016/j.geomorph.2010.08.009.

Bažant, Z. P., G. Zi, and D. McClung (2003), Size effect law and fracture mechanics of the triggering of dry snow slab avalanches, J. Geophys. Res., 108, B22119, doi:10.1029/2002JB001884.

Bennett, R. H., J. T. Burns, T. L. Clarke, J. R. Faris, E. B. Forde, and A. F. Richards (1982), Piezometer probe for assessing effective stress and stability in submarine sediments, in Marine Slides and Other Mass Movements, edited by S. Saxov, J. K. Nieuwenhuis, pp. 129-161. 
Berndt, C., J. Mienert. M. Vanneste, and S. Bunz (2005), Gas hydrate dissociation and sea floor collapse in the wake of the Storegga Slide, Norway, in Onshore-Offshore Relationships on the North Atlantic Margin (Proc. Norwegian Petrol. Soc. Conf., Trondheim, Norway, 2002), eds. B. T. G. Wandås, J. P. Nystuen, E. Eide, and F. M. Gradstein, Norwegian Petroleum Society Special Publication, Vol. 12, Elsevier, 285292, doi:10.1016/S0928-8937(05)80055-4.

Bilby, B. A., and J. D. Eshelby (1968), Dislocations and theory of fracture, in Fracture, An Advanced Treatise, vol. 1, edited by H. Liebowitz, pp. 99-182, Academic, San Diego, Calif.

Bishop A. W., G. E. Green, V. K. Garga, A. Andersen, and J. D. Brown (1971), A new ring shear apparatus and its application to the measurement of residual strength, Géotechnique, 21(4), $273-328$.

Bizzarri, A. W., (2010), How to promote earthquake ruptures: Different nucleation strategies in a dynamic model with slipweakening friction, B. Seismol. Soc. Am., 100(3), 923-940, doi: $10.1785 / 0120090179$.

Bjerrum, L., and K. Y. Lo (1963), Effect of aging on the shear-strength properties of a normally consolidated clay, Géotechnique, 13(2), 147-157.

Blum, J. A., C. D. Chadwell, N. Driscoll, and M. A. Zumberge (2010), Assessing slope stability in the Santa Barbara Basin, California, using seafloor geodesy and CHIRP seismic data, Geophys. Res. Lett., 37, L13308, doi:10.1029/2010GL043293.

Bryant, W. R., W. Hottman, and P. Trabant (1975), Permeability of unconsolidated and consolidated marine sediments, Gulf of Mexico, Mar. Georesour. Geotec., 1(1), 1-14.

Bünz, S., J. Mienert, and C. Berndt (2003), Geological controls on the Storegga gas-hydrate system of the mid-Norwegian continental margin, Earth Planet Sc. Lett., 209, 291-307 doi:10.1016/S0012-821X(03)00097-9.

Carrubba, P., and M. Del Fabbro (2008), Laboratory investigation on reactivated residual strength, J. Geotech Geoenviron., 134(3), 302-315, doi:10.1061/(ASCE)10900241(2008)134:3(302).

Cathles, L. M., Z. Su, and D. Chen (2010), The physics of gas chimney and pockmark formation, with implications for assessment of seafloor hazards and gas sequestration, Mar. Petrol. Geol., 48(1), 83-101.

Cleary, M. P., and J. R. Rice (1974), Some elementary models for the growth of slip surfaces in progressive failure, Rep. $M R L$ E-91, Brown Univ. Division of Engineering, Material Science Program, Providence, Rhode Island.

Cooper, M. R., E. N. Bromhead, D. J. Petley, D. I. Grant (1998), The Selborne cutting stability experiment, Géotechnique, 48(1), 83-101.

Corbett, D. R., B. McKee, M. Allison, (2006), Nature of decadalscale sediment accumulation on the western shelf of the Mississippi River delta, Continental Shelf Research, 26, 2125-2140.

Dieterich, J. H., (1992), Earthquake nucleation on faults with rate- and state-dependent strength, Tectonophysics, 211(1-4), 115-134, doi:10.1016/0040-1951(92)90055-B.

Edwards, B. D., H. J. Lee and M. E. Field (1995), Mudflow generated by retrogressive slope failure, Santa Barba Basin, California Continental Borderland, J. Sediment. Res., A65(1), 57-68.

Erdogan, F., and G. D. Gupta (1972), On the numerical solutions of integral equations, Q. Appl. Math, 289, 288-291.

Erdogan, F., G. D. Gupta, and T. S. Cook (1973), Numerical solution of integral equations, in Methods of Analysis and Solutions of Crack Problems, edited by G. C. Sih, pp. 368-425, Noordhoff, Leyden.

Faulkner, D. R., T. M. Mitchell, J. Behnsen, T. Hirose, and T. Shimamoto (2011) Stuck in the mud? Earthquake nucleation and propagation through accretionary forearcs, Geophys. Res. Lett., 38, L18303, doi:10.1029/2011GL048552.

Flemings, P. B., X. Liu, and W. J. Winters (2003), Critical pressure and multiphase flow in Blake Ridge gas hydrates, Geology, 31 (12), 1057-1060.

Garagash, D., L. N. Germaovich, L. C. Murdoch, S. J. Martel, Z. Reches, D. Elsworth, and T. C. Onstott (2009), A thermal technique of fault nucleation, growth, and slip, EOS Trans. $A G U, 90(52)$, Fall Meet. Suppl., Abstract H23E-0995.

Garagash, D. I., and L. N. Germaovich (2011), Nucleation of dynamic slip on a pressurized fault, to be submitted to Proc. $R$. Soc., Ser. A.
Gay, A., M. Lopez, C. Berndt, and M. Séranne (2007), Geological controls on focused fluid flow associated with seafloor seeps in the Lower Congo Basin, Mar. Geol., 244, 68-92, doi:10.1016/j.margeo.2007.06.003.

Gee, M. J. R., R. L. Gawthorpe, and J. S. Friedmann (2005), Giant striations at the base of a submarine landslide, Mar. Geol., 214, 287-294, doi:10.1016/j.margeo.2004.09.003.

Gerasoulis, A., and R. P. Srivastav (1981), A method for the numerical solution of singular integral equations with a principal value integral, Int. J. Eng. Sci., 19, 1293-1298.

Gibson, R. E. (1958), The progress of consolidation in a clay layer increasing in thickness with time, Géotechnique, 8(4),171-183.

Gomberg, J., P. Bodin, W. Savage, M. E. Jackson (1995), Landslide faults and tectonic faults, analogs?: The Slumgullion earthflow, Colorado, Geology, 23(1),41-44.

Goren, L., E. Aharonov, and M. H. Anders (2010), The long runout of the Heart Mountain landslide: Heating, pressurization, and carbonate decomposition, J. Geophys. Res., 115, B10210, doi:10.1029/2009JB007113.

Haacke, R. R. (2007), Gas hydrate, fluid flow and free gas: Formation of the bottom-simulating reflector, Earth Planet Sc. Lett., 66, 407-420.

Head, A. K. (1953), Edge dislocations in inhomogeneous media, Proc. Phys. Soc. B, 66, 793-801.

Henry, P. (2000), Fluid flow at the toe of the Barbados accretionary wedge constrained by thermal, chemical, and hydrogeologic observations and models, J. Geophys. Res., 105, 25,85525,872 .

Ida, Y. (1972), Cohesive force across the tip of a longitudinalshear crack and Griffith's specific surface energy, J. Geophys. Res., 77(20), 3796-3805.

Karig, D. E., and M. V. S. Ask (2005), Geological perspectives on consolidation of clay-rich marine sediments, J. Geophys. Res., 108, B42197, doi:10.1029/2001JB000652.

Kayen, R. E., and H. J. Lee (1991), Pleistocene slope instability of gas hydrate-laden sediment on the Beaufort Sea margin, Mar. Geotechnol., 10, 125-141.

Kilburn, C. R. J., and D. N. Petley (2003), Forecasting giant, catastrophic slope collapse: lessons from Vajont, Northern Italy, Geomorphology, 54, 21-32.

Krenk, S. (1975), On the use of the interpolation polynomial for solutions of singular integral equations, Q. Appl. Math, 32, 479-484.

Kvenvolden, K. A. (1993), Gas hydrates - Geological perspectives and global change, Rev. Geophys.., 31(2), 173-187.

Lapusta, N., J. R. Rice, Y. Ben-Zion, and G. Zheng (2000), Elastodynamic analysis for slow tectonic loading with spontaneous rupture episodes on faults with rate- and statedependent friction, J. Geophys. Res., 105(B10), 23,76523,789, doi:10.1029/2000JB900250.

Liu, X., and P. B. Flemings (2007), Dynamic multiphase flow model of hydrate formation in marine sediments, J. Geophys. Res., 112, B03101, doi:10.1029/2005JB004227.

Long, H., P. B. Flemings, J. T. Germaine, D. M. Saffer, and B. Dugan (2008), Data report: consolidation characteristics of sediments from IODP Expedition 308, Ursa Basin, Gulf of Mexico, in Proc. IODP, 308, edited by P. B. Flemings, J. H. Berhmann, C. M. John, and the Expedition 308 Scientists, Integrated Ocean Drilling Program Management International, Inc., College Station, Tex., doi:10.2204/iodp.proc.308.204.2008.

Martel, S. J., (2004), Mechanics of landslide initiation as a shear fracture phenomenon, Mar. Geol., 203, 319-339.

McClung, D. M., (1979), Shear fracture precipitated by strain softening as a mechanism of dry slab avalanche release, J. Geophys. Res., 84(B7), 3519-3526.

McClung, D. M., (2009), Dry snow slab quasi-brittle fracture initiation and verification from field tests, J. Geophys. Res., 114, F01022, doi:10.1029/2007JF000913.

McClure, M., and R. Horne (2010), Modeling slip during fluid injection and production using rate/state friction, Abstract H31G-1093 presented at 2010 Fall Meeting, AGU, San Francisco, Calif., 13-17 Dec.

Montgomery, D. R., K. M. Schmidt, W. E. Dietrich, J. McKean (2009), Instrumental record of debris flow initiation during natural rainfall: Implications for modeling slope stability, $J$. Geophys. Res., 114, F01031, doi:10.1029/2008JF001078.

Muller, J. R. and S. J. Martel, (2000), Numerical models of translational landslide rupture surface growth, Pure Appl. Geophys., 157, 1009-1038. 
Noda, H. and N. Lapusta, (2000), Rich fault behavior due to combined effect of rate strengthening friction at low slip rates and coseismic weakening: implications for Chi-Chi and Tohoku earthquakes, Abstract T42C-03 presented at 2011 Fall Meeting, AGU, San Francisco, Calif., 5-9 Dec.

Ochiai, H., Y. Okada, Gen Furuya, Y. Okura, T. Matsui, T. Sammori, T. Terajima, and K. Sassa (2004), A fluidized landslide on a natural slope by artificial rainfall, Landslides, 1, 211-219.

Palmer, A. C., and J. R. Rice (1973), The growth of slip surfaces in the progressive failure of over-consolidated clay, Proc. $R$. Soc. London, Ser. A, 332, 527-548.

Pellegrino, A., T. Picarelli, and G. Urciuoli (2004), Experiences of mudslides in Italy, in Proc. Int. Workshop on Occurrence and Mechanisms of Flow-Like Landslides in Natural Slopes and Earthfills, May 14-16, 2003, Sorrento, Italy, ed. L. Picarreli, Pàtron Editore, Bologna, Italy, 191-206.

Petley, D. N., T. Higuchi, D. J. Petley, M. H. Bulmer, and J. Carey (2005), Development of progressive landslide failure in cohesive materials, Geology, 33(3), 201-204.

Picarelli, L., C. Russo, and G. Urciuoli (1995), Modeling earthflows based on experiences, in Proc. 11th European Conference on Soil Mechanics and Foundation Engineering, Copenhagen, Denmark, 28 May - 1 June 1995, Danish Geotechnical Society, Copenhagen, Denmark, 157-162.

Picarelli, L., G. Urciuoli, M. Ramondini, and L. Comegna (2005), Main features of mudslides in tectonised highly fissured clay shales, Landslides, 2, 15-30.

Pinet, N., M. Duchesne, D. Lavoie, A. Bolduc, and B. Long (2008), Surface and subsurface signatures of gas seepage in the St. Lawrence Estuary (Canada): Significance to hydrocarbon exploration, Mar. Petrol. Geol., 25(3), 271-288.

Potts, D. M., N. Kovacevic, and P. R. Vaughan (2008), Delayed collapse of cut slopes in stiff clay, Géotechnique, 47(5), 953982.

Prindle, R. W, and A. A Lopez (1983), Pore pressures in marine sediments - 1981 test of the geotechnically instrumented seafloor probe (GISP), Annu. Proc. Offshore Technol. Conf., Abstract 4463, 8 pp.

Puzrin, A. M., L. N. Germaovich, and S. Kim (2004), Catastrophic failure of submerged slopes in normally consolidated sediments, Géotechnique, 54(10), 631-643.

Puzrin, A. M., and L. N. Germaovich (2005), The growth of shear bands in the catastrophic failure of soils, Proc. R. Soc., Ser. A, 461, 1199-1228.

Revil, A., and L. M. Cathles III (2002), Fluid transport by solitary waves along growing faults A field example from the South Eugene Island Basin, Gulf of Mexico, Earth Planet. Sci. Lett., 202, 321-335.

Rice, J. R. (1968), A path independent integral and the approximate analysis of strain concentration by notches and cracks, J. Appl. Mech., 35, 379-386.

Rice, J. R. (1992) Fault stress states, pore pressure distributions, and the weakness of the San Andreas Fault, in Fault Mechan ics and Transport Properties in Rocks, eds. B. Evans and T.-F. Wong, Academic Press, 475-503.

Rice, J. R., and K. Uenishi (2010), Rupture nucleation on an interface with a power-law relation between stress and displacement discontinuity, Int. J. Fracture, 163, 1-13, doi: 10.1007/s10704-010-9478-5.

Ripperger, J., J.-P. Ampuero, P. M. Mai, and D. Giardini (2007), Earthquake source characteristics from dynamic rupture with constrained stochastic fault stress, J. Geophys. Res., 112, B04311, doi:10.1029/2006JB004515

Rubin, A. M., and J.-P. Ampuero (2005), Earthquake nucleation on (aging) rate and state faults, J. Geophys. Res., 110, B11312, doi:10.1029/2005JB003686.

Rubin, A. M., and J.-P. Ampuero (2009), Self-similar slip pulses during rate-and-state earthquake nucleation, J. Geophys. Res., 114, B11305, doi:10.1029/2009JB006529.

Screaton, E. J., D. R. Wuthrich, and S. J. Dreiss (1990), Permeabilities, fluid pressures, and flow rates in the Barbados Ridge Complex, J. Geophys. Res., 95 (B6), 8,997-9,007, doi:10.1029/JB095iB06p08997.

Stark, T. D., and M. Hussain (2005), Shear strength in preexisting landslides, J. Geotech. Geoenviron., 136(7), 957-962, doi:10.1061/(ASCE)GT.1943-5606.0000308.
Stark, T. D., H. Choi, and S. McCone (2005), Drained shear strength parameters for analysis of landslides, J. Geotech. Geoenviron., 131(5), 575-588, doi:10.1061/(ASCE)10900241(2005)131:5(575).

Sultan, N., B. Marsset, S. Ker, T. Marsset, M. Voisset, A. M. Vernant, G. Bayon, E. Cauquil, J. Adamy, J. L. Colliat, and D. Drapeau, (2010), Hydrate dissolution as a potential mechanism for pockmark formation in the Niger delta, J. Geophys. Res., 115, B08101, doi:10.1029/2010JB007453.

Tanikawa, W., T. Shimamoto, S. K. Wey, C. W. Lin, and W. C. Lai (2008), Stratigraphic variation of transport properties and overpressure development in the Western Foothills, Taiwan, $J$. Geophys. Res., 113, B12403, doi:10.1029/2008JB005647.

Templeton, E. L., and J. R. Rice (2008), Off-fault plasticity and earthquake rupture dynamics: 1. Dry materials or neglect of fluid pressure changes, J. Geophys. Res., 113, B09306, doi:10.1029/2007JB005529.

Tse, S. T., and J. R. Rice (1986), Crustal earthquake instability in relation to the depth variation of frictional properties, J. Geophys. Res., 91(B9), 9452-9472, doi:10.1029/JB091iB09p09452.

Uenishi, K., and J. R. Rice (2003), Universal nucleation length for slip-weakening rupture instability under nonuniform fault loading, J. Geophys. Res., 108, B12042, doi:10.1029/2001JB00168.

Viesca-Falguières, R. C., and J. R. Rice (2010), Anticipated arrest: Insufficient conditions for continued dynamic propagation of a slip-weakening rupture nucleated by localized increase of pore-pressure, Proc. and Abstracts SCEC Ann. Meet., XX, Abstract 2-036

Viesca, R. C., and J. R. Rice (2010), Modeling slope instability as shear rupture propagation in a saturated porous medium, in Submarine Mass Movements and Their Consequences (Proc. 4th Int. Symp., Austin, Tex., 8-11 November 2009), eds. D. C. Mosher, R.C. Shipp, L. Moscardelli, J. D. Chaytor, C. D. P. Baxter, H. J. Lee, and R. Urgeles, Advances in Natural and Technological Hazards Research, Vol. 28, Springer-Verlag, New York, 215-225, doi: 10.1007/978-90-481-3071-9_18.

Viesca, R. C., and J. R. Rice (2011), Elastic reciprocity and symmetry constraints on the stress field due to a surface-parallel distribution of dislocations, J. Mech. Phys. Solids, 59, 753757, doi:10.1016/j.jmps.2011.01.011.

Viesca, R. C., E. L. Templeton, and J. R. Rice (2008), Offfault plasticity and earthquake rupture dynamics: 2. Effects of fluid saturation, J. Geophys. Res., 113, B09307, doi:10.1029/2007JB005530.

Vardoulakis, I. (2002), Dynamic thermo-poro-mechanical analysis of catastrophic landslides, Gèotechnique, 52(3), 157-171.

Voight, B., and C. Faust (1982), Frictional heat and strength loss in some rapid landslides Gèotechnique, 32(1), 43-54.

Wen, B.-P., and A. Aydin, (2003), Microstructural study of a natural slip zone: quantification and deformation history, Eng. Geol., 68, 289-317.

Wen, B.-P., and A. Aydin, (2004), Deformation history of a landslide slip zone in light of soil microstructure, Env. Eng. Geosci., X(2), 123-149.

Westbrook, G. K., K. E. Thatcher, E. J. Rohling, A. M. Piotrowski, H. Pälike, A. H. Osborne, E. G. Nisbet, T. A. Minshull, M. Lanoisellé, R. H. James, V. Hühnerbach, D. Green, R. E. Fisher, A. J. Crocker, A. Chabert, C. Bolton, A. Beszczynska-Möller, C. Berndt, and A. Aquilina, (2009), Escape of methane gas from the seabed along the West Spitsbergen continental margin, Geophys. Res. Lett., 36, L15608, doi:10.1029/2009GL039191.

Wiberg, N.-E., M. Koponen, and K. Runesson (1990), Finite element analysis of progressive failure in long slopes, Int. J. Numer. Anal. Met., 14, 599-612.

$\mathrm{Xu}, \mathrm{W}$. and L. N. Germanovich (2006), Excess pore pressure resulting from methane hydrate dissociation in marine sediments: A theoretical approach, J. Geophys. Res., 111, B01104, doi:10.1029/2004JB003600.

J. R. Rice, R. C. Viesca, School of Engineering and Applied Sciences, Harvard University, 29 Oxford Street, Pierce Hall, Cambridge, MA 02138, USA. (rice@seas.harvard.edu,viesca@post.harvard.edu) 